\title{
Benign Extramedullary Tumors of the Foramen Magnum
}

\author{
B. Guidetti and A. Spallone \\ Division of Neurosurgery, Department of Clinical Neurological Sciences, \\ University of Rome "La Sapienza", School of Medicine, Rome (Italy) \\ With 13 Figures
}

\section{Contents}

Introduction ............................................... 84

Anatomy of the Region of the Foramen Magnum .................. 84

Tumors of the Foramen Magnum. Frequency and Site............... 85

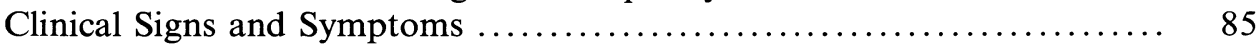

Neurological Examination.................................... 91

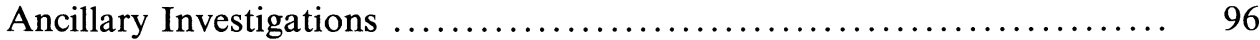

Neurophysiological Investigations . . . . . . . . . . . . . . . . . . . . . 96

Lumbar Puncture .......................................... 99

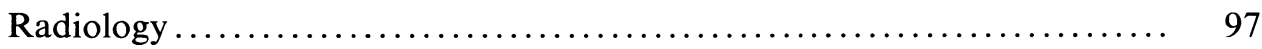

Plain Roentgenograms ...................................... 97

Air Studies and Contrast Ventriculography $\ldots \ldots \ldots \ldots \ldots \ldots \ldots \ldots \ldots . \quad 98$

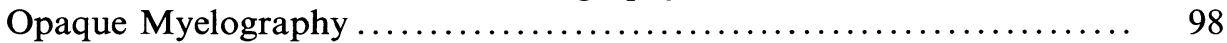

Angiography............................................. 101

Computed Tomography......................................... 104

Nuclear Magnetic Resonance.................................. 104

Operative Management...................................... 106

Operative Approach....................................... 106

Anesthesia .............................................. 106

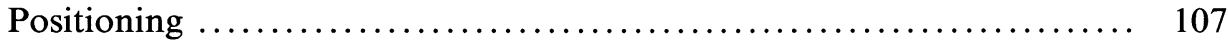

Technique .............................................. 108

Transcervical Transclival Approach $\ldots \ldots \ldots \ldots \ldots \ldots \ldots \ldots \ldots \ldots \ldots, 114$

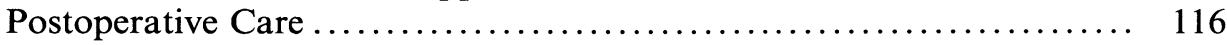

Clinical Results .......................................... 116

References................................................. 117 


\section{Introduction}

Masses located at the craniovertebral junction comprise a variety of neoplastic and non-neoplastic processes, which have in common an insidious, often bizarre, clinical course resembling that of degenerative diseases of the nervous system, due to the frequent coexistence of signs of both posterior fossa and long tract involvement.

A substantial body of literature has dealt with tumors of the foramen magnum. Under this label, cases have been reported of either intra-axial or extra-axial tumors located at the level of the craniocervical junction and/or high cervical region, whether or not they extend into the posterior fossa (Cohen 1975).

In a 1980 paper (Guidetti and Spallone 1980) we stressed that the term "foramen magnum tumors" should be confined to tumors extending, symmetrically or asymmetrically, into both posterior fossa and spinal canal, as previously proposed by Arseni and Ionesco (1960). Following the guidelines of Cushing and Eisenhard (1938), we defined our cases as craniospinal or spinocranial according to the predominant location and site of origin, intracranial or high cervical. This chapter considers benign extra-axial tumors of the foramen magnum whose histology makes them potentially curable and thus of extreme interest to clinicians. On the other hand, the difficulty of the clinical, and sometimes of the radiological, diagnosis and treacherous location of these lesions, make them a formidable challenge for those involved in their clinical management.

\section{Anatomy of the Region of the Foramen Magnum}

The occipital bone surrounding the foramen magnum, the atlas and the axis with their complex osteo-ligamentous relationship together constitute the craniocervical junction, a detailed anatomical description of which is beyond the scope of the present study because we consider only intradural masses located at the foramen magnum.

Relevant neurovascular structures located intradurally at the level of the foramen magnum are the laterally situated first and second cervical roots, the anterolateral spinal accessory nerves and the vertebral arteries as they course intradurally from the lateral to the anterior surface of the medulla and give rise to the unpaired anterior spinal artery. The PICA originates from the vertebral artery, in most cases close to the foramen magnum, and the hypoglossal nerve arises from the anterior medulla, just above the level of the foramen and courses anterolaterally to emerge from the hypoglossal canal. All these structures may easily be affected by intradural foramen magnum masses which, in their upward extension, may even dislodge the IX-X complex, the basilar artery and, more rarely, other cerebellopontine angle nerves, and inferiorly may reach occasionally $\mathrm{C}_{3}$ as 
well as lower cervical roots. Involvement of the cord (at the cervico-medullary junction) is obviously a constant feature and that of the cerebellum not uncommon, according to the site of the mass.

Since the upper limit of the cord is arbitrarily fixed at the level of the origin of the first cervical root, the foramen magnum is occupied by the medulla. At this level, there is the decussation of the pyramidal tracts, which interrupts the anterior median sulcus, whilst posteriorly the fasciculi gracilis and cuneatus continue without distinction from medulla to cord, without any change in the appearance of the posterior surface.

We refer the reader to specific publications for the topographical anatomy of the cervico-medullary junction (Delmas 1975; Netter 1983).

\section{Tumors of the Foramen Magnum. Frequency and Site}

Intradural extramedullary tumors of the foramen magnum account for 2.5 to $10 \%$ of all intraspinal masses and for approximately $1 \%$ of all brain tumors (Table 1). Meningiomas and neurofibromas are the most common benign extramedullary tumors located in this region. Cases of teratoma and epidermoid have also been reported (Abrahamson and Grossman 1923; Aring 1974; Elsberg and Strauss 1929; Weinstein and Wechsler 1940; Yasuoka et al. 1978).

Reports of lipoma (Bucy and Gustafson 1938; Misch 1935), cavernous hemangioma (MacCarty et al. 1959), and meningeal melanocytoma (Limas and Tio 1972) are exceptional.

Table 2 summarizes oncotype and site together with the age and sex of the patients with foramen magnum tumors observed in our institution. Meningioma was the most common histological subtype. As in other large series (Yasuoka et al. 1978), the meningioma: neurinoma ratio was 2:1. Neurinomas originate most commonly from the $\mathrm{C}_{2}$ root. Most of the lesions were located anterolaterally, although 6 out of 26 were located anteriorly to the cord and these represented a considerable surgical challenge.

\section{Clinical Signs and Symptoms}

Several authors (Cohen 1975) have drawn attention to the protean clinical presentation of tumors of the foramen magnum. A long, often remitting, clinical course is commonly observed in patients with these lesions. The time between onset of symptoms and diagnosis in our first 18 patients averaged three and a half years, ranging from three months to 13 years. The interval in the more recent 8 cases was similar. The interval between was also remarkable in these patients: 14 months on average (range: 20 days- 5 years). However, the rather long time usually required for a correct diagnosis and appropriate treatment is explained by the fact that misdiagnosis is not uncommon and patients are treated for some other disease, 
B. Guidetti and A. Spallone

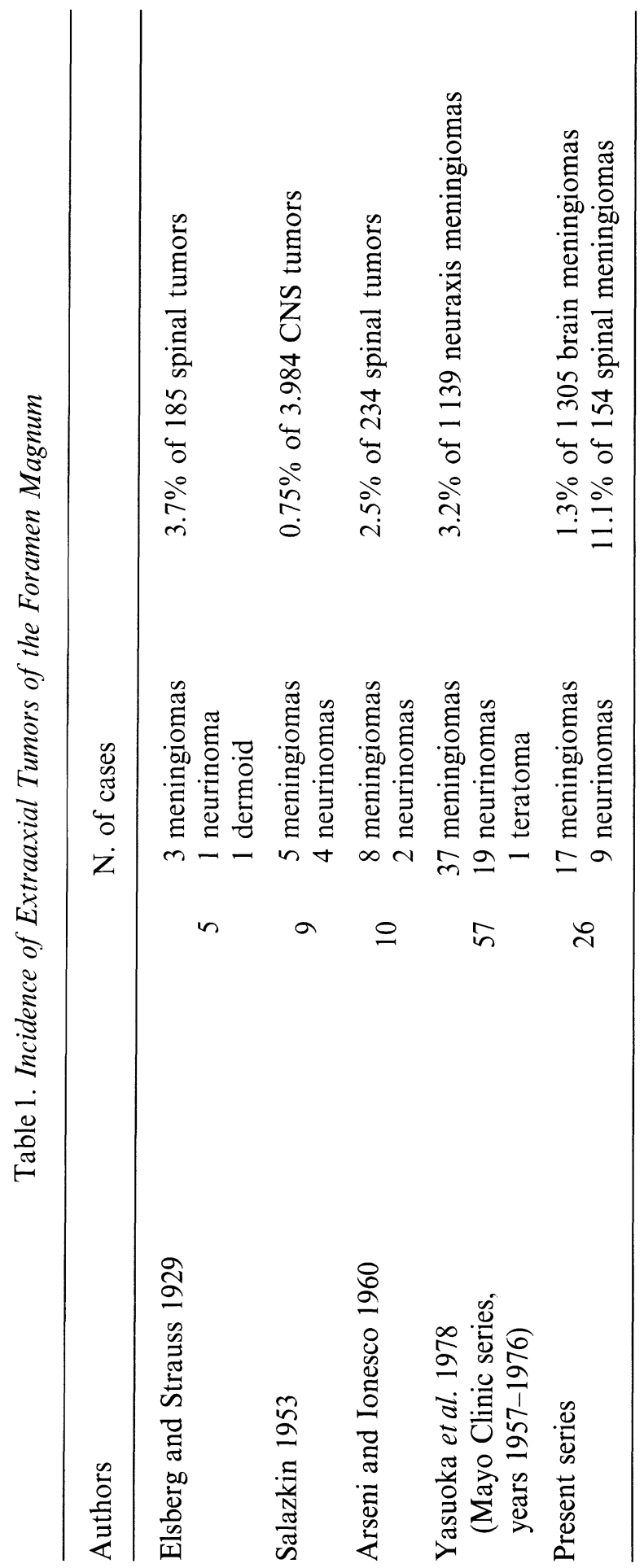


Table 2. Localization and Oncotypes

\begin{tabular}{cllll}
\hline Case & Sex & Age & Localization & Histology \\
\hline 1 & $\mathrm{f}$ & 35 & L. antero-lateral spinocranial & meningioma \\
2 & $\mathrm{f}$ & 57 & anterior craniospinal & meningioma \\
3 & $\mathrm{f}$ & 26 & R. antero-lateral hourglass & $\mathrm{C}_{1}$ neurinoma \\
4 & $\mathrm{f}$ & 51 & R. anterior hourglass & $\mathrm{C}_{2}$ neurinoma \\
5 & $\mathrm{~m}$ & 60 & L. antero-lateral craniospinal & meningioma \\
6 & $\mathrm{~m}$ & 30 & R. postero-lateral hourglass & $\mathrm{C}_{2}$ neurinoma \\
7 & $\mathrm{~m}$ & 26 & R. antero-lateral craniospinal & meningioma \\
8 & $\mathrm{f}$ & 53 & R. antero-lateral spinocranial & meningioma \\
9 & $\mathrm{~m}$ & 40 & R. antero-lateral & $\mathrm{C}_{1}$ neurinoma \\
10 & $\mathrm{f}$ & 44 & L. antero-lateral craniospinal & meningioma \\
11 & $\mathrm{~m}$ & 20 & R. antero-lateral craniospinal & meningioma \\
12 & $\mathrm{f}$ & 40 & L. postero-lateral craniospinal & meningioma \\
13 & $\mathrm{f}$ & 31 & L. anterior & $\mathrm{C}_{2}$ neurinoma \\
14 & $\mathrm{f}$ & 43 & anterior craniospinal & meningioma \\
15 & $\mathrm{f}$ & 65 & anterior spinocranial & meningioma \\
16 & $\mathrm{f}$ & 13 & L. anterior & $\mathrm{C}_{2}$ neurinoma \\
17 & $\mathrm{f}$ & 43 & L. postero-lateral spinocranial & meningioma \\
18 & $\mathrm{~m}$ & 25 & L. anterior hourglass & $\mathrm{C}_{2}$ neurinoma \\
19 & $\mathrm{f}$ & 51 & anterior craniospinal & meningioma \\
20 & $\mathrm{f}$ & 54 & L. antero-lateral hourglass & $\mathrm{C}_{2}$ neurinoma \\
21 & $\mathrm{f}$ & 50 & L. antero-lateral & $\mathrm{C}_{1}$ neurinoma \\
22 & $\mathrm{f}$ & 39 & R. antero-lateral spinocranial & meningioma \\
23 & $\mathrm{~m}$ & 20 & R. antero-lateral spinocranial & meningioma \\
24 & $\mathrm{~m}$ & 50 & L. antero-lateral spinocranial & meningioma \\
25 & $\mathrm{~m}$ & 72 & L. antero-lateral craniospinal & meningioma \\
26 & $\mathrm{f}$ & 48 & R. postero-lateral craniospinal & meningioma \\
\hline & & & &
\end{tabular}

Table 3. Erroneous Diagnoses Made in Our Patients

\begin{tabular}{llr}
\hline Diagnosis & N. of cases & $\%$ \\
\hline Multiple sclerosis & 6 & 23.1 \\
Spondylotic myelopathy & 6 & 23.1 \\
Syringomyelia & 1 & 3.9 \\
Intraaxial tumor & 2 & 7.7 \\
Vascular disease & 2 & 7.7 \\
\hline
\end{tabular}

In two patients diagnosis of multiple sclerosis preceded another erroneous diagnosis. 
sometimes with spectacular symptomatic relief, before a foramen magnum mass is suspected. Table 3 summarizes the diseases for which 14 of our patients were long treated. It is noteworthy that three of them underwent surgery elsewhere for the presumed lesion, intra-axial tumor in two cases, cervical spondylosis in the third, with significant-temporary relief of symptoms, before the correct diagnosis could be established. Five more cases, for a total of 8 out $26(30 \%)$, had significant remissions, whether or not related to medical and/or physical treatment is not known, which obviously contributed to the long delay between onset of symptoms and tumor surgery. Yasuoka et al. (1978) dealt exhaustively with the problem of differential diagnosis from diseases that a tumor of the foramen magnum may simulate. They include cervical spondylosis, multiple sclerosis, syringomyelia, intramedullary tumor, Arnold-Chiari malformation, carpal tunnel syndrome, normal pressure hydrocephalus, amyotrophic lateral sclerosis and basilar impression. A more recent report from another Mayo Clinic group (Meyer et al. 1984) claimed that in three out of their 102 cases of benign tumors of the foramen magnum lumbar spine disease was suspected since the patients presented with dysesthesia of one lower limb. "Vascular disease" was the misdiagnosis attached to two of our patients before they were seen here.

Attempts to define a typical clinical syndrome of tumors of the foramen magnum have generally been unrewarding. Blom and Ekbom (1962) described "early clinical signs" of these lesions, pseudoastereognosis (Arseni and Ionesco 1960) or "piano-playing fingers" phenomenon being the most peculiar. However this symptom, also called tabetic pseudoathetosis (Blom and Ekbom 1962) or stereoanesthesia (Rubinstein 1938; Weinstein and Wechsler 1940), consisting of clumsiness of the hands with loss of position sense and of ability to recognize the size and the shape of objects in spite of normal primary sensation, was reported by no more than one third of our patients as in others' (Yasuoka et al. 1978). Suboccipital and/or neck pain is a common early symptom of these lesions. It was the first symptom in three quarters of our patients (Table 4).

It is usually worse on the tumor side, insidious in onset, often mild and easily relieved by common analgesics. It may be exacerbated by movements of the neck and so may easily be attributed to cervical spondylosis. In the early stage of the disease anything which increases intraspinal pressure such as sneezing, coughing etc, may exacerbate this pain but not as a rule in the later stage of tumor development. Sensory disturbances in the form of paresthesias, and cold or burning dysesthesias are another early symptom of these lesions. Yasuoka et al. (1978) describe two stages of clinical progression of tumors of the foramen magnum. In the first stage suboccipital and/or neck pain dysesthesias, usually of the upper limbs, are the only complaints, which are commonly attributed to cervical spondylosis. At this 
Table 4. Early Clinical Symptoms in Our Cases

\begin{tabular}{|c|c|c|c|c|}
\hline \multirow[t]{2}{*}{ Symptoms } & \multicolumn{2}{|c|}{ First symptom } & \multicolumn{2}{|c|}{ Second symptom } \\
\hline & $\begin{array}{l}\text { N. of } \\
\text { cases }\end{array}$ & $\%$ & $\begin{array}{l}\text { N. of } \\
\text { cases }\end{array}$ & $\%$ \\
\hline $\begin{array}{l}\text { Suboccipital } \\
\text { and/or neck pain }\end{array}$ & 20 & 76.9 & 2 & 7.7 \\
\hline Cold dysesthesias & 3 & 11.5 & 3 & 11.5 \\
\hline $\begin{array}{l}\text { Headache, vomiting, } \\
\text { diplopia }\end{array}$ & 2 & 7.7 & 3 & 11.5 \\
\hline $\begin{array}{l}\text { Paresthesias } \\
\quad \text { (tingling, numbness, etc) }\end{array}$ & 0 & - & 8 & 30.8 \\
\hline Weakness of upper limbs & 1 & 3.9 & 8 & 30.8 \\
\hline Weakness of lower limbs & 0 & - & 4 & 15.4 \\
\hline Burning dysesthesias & 0 & - & 1 & 3.9 \\
\hline Sphincter disturbances & 0 & - & 1 & 3.9 \\
\hline
\end{tabular}

stage the neurological examination is usually non-contributory. Later, weakness of the extremities, sensory disturbances, not uncommonly with "cape distribution", and urinary problems occur, symptoms that may suggest an intramedullary lesion as the underlying problem. However, although this staging is broadly acceptable, it may not apply to all cases. Weakness of an upper limb was an early symptom (either the first or the second) in one third of our patients and weakness of a lower limb in $15 \%$. Bogorodinskij (1936) and Cohen and McRae (1962) considered that progressive weakness, which had been previously described by other authors (Elsberg 1925; Elsberg and Strauss 1929), was typical of foramen magnum tumors. Initially it involves one upper limb, then the ipsilateral lower limb, followed by the contralateral lower limb and finally by the contralateral upper limb. This pattern of progression of motor weakness was reported by approximately half of our patients (Table 5), but was not observed by Yasuoka et al. (1978) in their large series. These authors noted paraparesis of the upper extremities with lower limb monoparesis, but did not record cases of paraparesis of the lower extremities with upper limb monoparesis. Bogorodinskij (1936) described other forms of progression, such as paraparetic and mixed types of motor weakness. As stated above, paresthesias in the form of tingling and/or numbness are a frequent complaint of patients with foramen magnum tumors. They usually involve one or both upper limbs, and as a rule are considered to be due to cervical spondylosis. Occasionally 
Table 5. Clinical Symptomatology at the Admission

\begin{tabular}{lrl}
\hline Symptoms & N. of cases & $\%$ \\
\hline Suboccipital and/or neck pain & 26 & 100 \\
Headache, vomiting, diplopia & 6 & 23.1 \\
Motor weakness & 22 & 84.7 \\
"typical” progression * & 14 & 53.9 \\
atypical progression & 8 & 30.8 \\
Sensory disturbances & 20 & 76.9 \\
paresthesias & 12 & 46.1 \\
cold dysesthesias & 8 & 30.8 \\
burning dysesthesias & 5 & 19.2 \\
hypesthesias & 6 & 23.1 \\
Sphincter disturbances & 10 & 38.5 \\
Respiratory troubles & 6 & 23.1 \\
Hoarseness & 5 & 19.2 \\
Dysphagia & 4 & 15.4 \\
Hormonal disturbances & 1 & 3.9 \\
\hline
\end{tabular}

* Weakness of one upper limb, followed by the ipsilateral lower limb, then by the controlateral lower limb, finally by the controlateral upper limb.

they may affect the lower extremities, thus simulating a lumbar spinal disease (Meyer et al. 1984).

Cold dysesthesias were described long ago in cases of tumors of the foramen magnum (Elsberg and Strauss 1929) and have been considered typical of these lesions (Beatty 1970). However their frequency ranges from less than $10 \%$ (Meyer et al. 1984) to approximately $30 \%$, as in our series. Furthermore it must be remembered that intramedullary lesions may also give rise to abnormal cold sensations in the extremities. Burning dysesthesias have also been described. They were reported by 5 of our patients $(19 \%)$ and typically preceded the onset of hypesthesia.

Bladder disturbances and respiratory trouble are encountered in the later stages of the clinical history of patients with tumors of the foramen magnum. Their frequency approximates $30 \%$ in our experience, but Meyer et al. reported recently (1984) that respiratory dysfunctions were present in only $6 \%$ of patients in the large Mayo Clinic series. Dysphagia and/or dysphonia are other not infrequent late symptoms of these lesions, their frequency averaging 10\% in our and in other series (Meyer et al. 1984). Occasional instances of hallucinations (Guidetti and Spallone 1980; Nittner 
1975), hormonal disturbances (Guidetti and Spallone 1980; Smolik and Sachs 1954), chronic hemifacial pain (Koempf and Botzler 1980) have also been described. Patients presenting with symptoms and signs of slowly progressing intracranial hypertension with few or no other relevant symptoms have also been described (Yasuoka et al. 1978). Symptoms indicating increased intracranial pressure, such as headache, vomiting and/or diplopia, were a major complaint in approximately a quarter of our patients.

The complex anatomy of the foramen magnum region may well explain the extreme variability of the clinical symptoms of these lesions. The subarachnoid space is relatively wide at this level, and may accommodate tumors up to a certain size with little or no harm to the neighbouring neurovascular structures. The latter may be involved later in different ways, depending on the actual location and growth pattern of the tumor. For example, tumors located anterolaterally are more likely to present clinically with the above "typical" progression of motor weakness, but are less likely to involve the posterior columns in such a way as to cause pseudoastereognosis. The latter is more likely to be related to anterior or posterior masses, which may exert pressure on the posterior columns either directly or by pushing them against the bone (Blom and Ekbom 1962). The involvement of the cranial nerves and of the upper cervical roots and its consequent clinical presentation obviously depends on the actual location of the mass.

In summary, the clinical manifestations of a tumor of the foramen magnum vary considerably. The occurrence of neck and/or suboccipital pain before symptoms and signs of long tract and cranial nerve involvement should lead to the suspicion of a mass located at the level of the cervicomedullary junction. Weakness starting and/or predominating in one upper limb may be another diagnostic clue, as well as astereognosis in the absence of other signs of parietal lobe involvement, such as sensory inattention and agraphesthesia. However the clinical diagnosis is virtually impossible at an early stage, and may remain very difficult even at an advanced stage.

\section{Neurological Examination}

The neurological findings in our patients at the time of admission are briefly summarized in Table 6 . Table 7 shows for comparison the percentages of the main neurological signs reported by the recently published large Mayo Clinic' series (Meyer et al. 1984). The neurological findings on admission are roughly similar in these two series of patients. Differences, such as those in the percentages of motor weakness, might perhaps be explained by the fact that a fair number of the Mayo Clinic patients $(20 \%)$ had a normal neurological examination on admission, while none of our patients was neurologically normal. 
Table 6. Neurological Findings in our Patients

\begin{tabular}{|c|c|c|c|}
\hline Signs & \multicolumn{2}{|c|}{ N. of cases } & $\%$ of cases \\
\hline Stiffness of the neck & \multicolumn{2}{|l|}{22} & 84.7 \\
\hline Lhermitte's sign & \multicolumn{2}{|l|}{2} & 7.7 \\
\hline $\begin{array}{l}\text { Motor weakness } \\
\text { ipsilat. hemiparesis } \\
\text { tetraparesis } \\
\text { triparesis } \\
\text { paraparesis }\end{array}$ & $\begin{array}{r}24 \\
9 \\
10 \\
3 \\
2\end{array}$ & & $\begin{array}{r}93.3 \\
34.7 \\
38.5 \\
11.5 \\
7.7\end{array}$ \\
\hline Increased tendon reflexes & \multicolumn{2}{|l|}{25} & 96.1 \\
\hline Atrophy of the hands & \multicolumn{2}{|l|}{9} & 34.7 \\
\hline Atrophy of the arms & \multicolumn{2}{|l|}{2} & 7.7 \\
\hline Sensory loss & \multicolumn{2}{|l|}{23} & 88.4 \\
\hline $\begin{array}{l}\text { Hypesthesia (pain, temp., } \\
\text { and/or touch) }\end{array}$ & \multirow{2}{*}{\multicolumn{2}{|c|}{$\begin{array}{cl}20 & \begin{array}{l}\text { controlat. } 15 \\
\text { bizarre location } 5 \\
8\end{array}\end{array}$}} & 76.9 \\
\hline $\mathrm{C}_{2}$ hypesthesia & & & 30.8 \\
\hline Loss of joint sensation & 14 & $\begin{array}{l}\text { ipsilat. } 8 \\
\text { over the entire body } 5 \\
\text { bizarre location } 1\end{array}$ & 53.9 \\
\hline $\begin{array}{l}\text { Pseudoastereognosia and/or } \\
\text { tabetic pseudoathetosis }\end{array}$ & \multicolumn{2}{|l|}{8} & 30.8 \\
\hline Nystagmus & \multicolumn{2}{|l|}{11} & 42.3 \\
\hline Dysmetria, ataxia, etc. & \multicolumn{2}{|l|}{6} & 23.1 \\
\hline Cranial nerve palsy & 15 & $\begin{array}{l}9 \mathrm{XI} \\
5 \mathrm{IX}-\mathrm{X} \\
4 \mathrm{~V} \\
2 \mathrm{VII}-\mathrm{VIII} \\
2 \mathrm{XII}\end{array}$ & 57.6 \\
\hline Papilledema & 2 & & 7.7 \\
\hline Bernard-Horner syndrome & 2 & & 7.7 \\
\hline
\end{tabular}

Involvement of the pyramidal tracts in the form of increased deep tendon reflexes and/or motor weakness was the most frequent neurological sign in patients with tumors of the foramen magnum on admission to the hospital. It was observed almost invariably in our cases. Hemiparesis ipsilateral to the lesion was a very frequent finding and was usually associated with sensory deficits of the Brown-Séquard type. The Babinsky sign is also present in the majority of patients with these lesions. 
Table 7. Incidence of Neurological Findings at Admission. Comparison Between Mayo Clinic' Series and Ours

\begin{tabular}{|c|c|c|}
\hline Sign & $\begin{array}{l}\text { Mayo Clinic } \\
\%\end{array}$ & $\begin{array}{l}\text { Present series } \\
\%\end{array}$ \\
\hline Increased tender reflexes & 70.6 & 96.1 \\
\hline Weakness & 67.6 & 93.3 \\
\hline $\begin{array}{l}\text { Sensory loss } \\
\text { pain and temperature } \\
\text { joint sensation } \\
\text { touch } \\
\text { dissociated loss } \\
\text { cape distribution } \\
\mathrm{C}_{2} \text { hypesthesia }\end{array}$ & $\begin{array}{r}37.3 \\
26.5 \\
21.6 \\
24.6 \\
6.8 \\
17.6\end{array}$ & $\begin{array}{r}46.1 \\
53.9 \\
30.8 \\
26.9 \\
7.7 \\
30.8\end{array}$ \\
\hline Brown-Séquard syndrom & 29.4 & 30.8 \\
\hline $\begin{array}{c}\text { Atrophy } \\
\text { hands } \\
\text { arms }\end{array}$ & $\begin{array}{r}12.8 \\
6.8\end{array}$ & $\begin{array}{r}30.8 \\
7.7\end{array}$ \\
\hline Ataxia incoordination & 37.3 & 23.1 \\
\hline Nystagmus & 24.5 & 42.3 \\
\hline $\begin{array}{l}\text { Cranial nerve palsy } \\
\text { V } \\
\text { VII-VIII } \\
\text { IX-X } \\
\text { XI } \\
\text { XII }\end{array}$ & $\begin{array}{c}5.9 \\
2 \\
13.6 \\
27.8 \\
7.8\end{array}$ & $\begin{array}{r}15.4 \\
7.7 \\
19.2 \\
34.7 \\
7.7\end{array}$ \\
\hline Papilledema & 6.8 & 7.7 \\
\hline Bernard-Horner syndrom & 3.9 & 7.7 \\
\hline
\end{tabular}

Sensory loss, that is hypesthesia for pain, temperature and/or touch is a very frequent finding, often "dissociated" ( $25 \%$ in our experience). A "cape distribution" suspended sensory loss may also be present, although in a minority of cases (around 7\% in ours as well as in Mayo Clinic's experience). This, combined with dissociated sensory loss may easily suggest an intramedullary lesion. Loss of joint sensation may also occur in most cases. When located ipsilaterally to the tumor, as in $30 \%$ of our patients, it may contribute to a Brown-Séquard pattern. Hypesthesia in the $C_{2}$ territory is a very important sign, which may prompt a clinical suspicion of a tumor of the foramen magnum. However, it was observed in no more than one third of the cases in some large series (Guidetti and Spallone 
1980; Meyer et al. 1984). In fact, foramen magnum tumors may not extend far enough into the spinal canal to encroach on the $C_{2}$ root in such a way as to cause hypesthesia. Krayenbühl (1973) has stated that the $C_{1}$ root also contains sensory fibers projecting into $\mathrm{C}_{2}$ territory, a fact which may explain the occurrence of occipital pain in the absence of objective signs of $\mathrm{C}_{2}$ root involvement.

A rather peculiar clinical sign indicating disturbances of deep sensation in the hands, frequently detected in patients with these tumors, is the pseudoastereognosis (Arseni and Ionesco 1960), otherwhere called tabetic pseudoathetosis (Blom and Ekbom 1962), stereoanesthesia (Rubinstein 1938; Weinstein and Wechsler 1940), "piano-playing fingers" phenomenon (Blom and Ekbom 1962) mentioned earlier. All these terms denote an inability to recognize objects placed in the hands without looking at them, and loss of position sense of the hands, which causes athetoid-like movements of the fingers if the patient is asked to hold up his arms with the eyes closed. In an attempt to account for this phenomenon, Blom and Ekbom (1962) suggested that chronic lesions of the dorsal columns might affect the cerebellar components of deep sensation of the arms while sparing those of the legs, which supposedly (Ferraro and Barrera 1934) pass through the lateral columns. If so, either anterior or posterior masses would be more likely to cause pseudoastereognosis. This sign was observed in approximately one third of the patients in our series and in others' (Meyer et al. 1984; Yasuoka et al. 1978). Obviously, it cannot be demonstrated unless the strength of the upper extremities is relatively intact (Blom and Ekbom 1962).

Atrophy of the intrinsic muscles of the hands is a relatively frequent finding - from $17 \%$ to $52 \%$ in several series (Stein et al. 1963; Yasuoka et al. 1978), 30\% in our experience-whose pathogenesis has still to be clarified. Most authors (Cohen and McRae 1962; Krayenbühl 1973; Liveson et al. 1973; Symonds and Meadows 1937; Yasuoka et al. 1978) agree that a mechanism of vascular compromise in the territory of the anterior spinal artery appears to be most likely. However, Stein et al. (1963) found no evidence of anterior horn cell damage in the lower cervical segments in a case of spinocranial meningioma with atrophy of the hands who came to autopsy without having undergone surgery. These authors stressed, however, that cellular changes might be too subtle to be detected by conventional microscopic examination.

The blood supply to the lower spinal segments is provided by the anterior spinal artery which anastomoses with the radiculo-medullary artery of the sixth cervical root (Lazorthes 1961). Therefore a possible role of the radicular medullary arteries in the pathogenesis of the supposed vascular damage underlying these lesions might also be considered.

A mechanism of venous engorgement and resulting cord edema has 
also been conjectured (Brain et al. 1952), but considered unlikely (Cohen and McRae 1962; Krayenbühl 1973), in view of the numerous anastomoses and weath of collaterals that the cervical veins possess. However, Taylor and Byrnes (1974) have recently observed venous stasis with capillary hemorrhages in the lower cervical cord of monkeys in which masses have been induced experimentally at the foramen magnum level.

A stretching mechanism related to anchoring of the compromised spinal cord to dentate ligaments was considered some time ago (Cohen and McRae 1962) and later suggested again by Bartal et al. (1972), in order to explain the phenomenon of atrophy of upper and lower extremities, that is occasionally observed in patients with foramen magnum tumors. However this hypothesis has not received wide attention.

Yasuoka et al. (1978) have recently suggested that enlargement of the central canal, possibly related to disturbances of the CSF flow due to the presence of a mass at the craniocervical junction, might explain most of the puzzling clinical signs observed in patients with these lesions, such as suspended sensory loss and intrinsic muscle atrophy. A case of syringomyelia associated with a foramen magnum meningioma has been described more recently (Hirata et al. 1985). Following removal of the lesion, this patient showed prompt recovery from his preoperative symptoms, namely upper arm atrophy and suspended sensory loss, a fact which would suggest "an interference with circulation rather than syringomyelia" as the likely pathogenetic mechanism. In this case, only delayed CT following intrathecal injection of contrast allowed demonstration of the syringomyelic cavity. In this respect, NMR might offer more consistently evidence of any central canal enlargement. In the only case of our series in which NMR was performed no syringomyelic cavity was detected although no atrophy of the hands was present.

Perhaps this problem might be solved by careful arteriographic studies of cases of foramen magnum tumors focused on the flow pattern of the anterior spinal artery and lower cervical radicular arteries, by means of digital subtraction angiography, combined with NMR and/or CT evaluation of possible enlargement of the central canal of the spinal cord. EMG results, although controversial (Yasuoka et al. 1978), might be also valuable for this purpose. Nystagmus, usually of the horizontal type, is another frequent finding (25-40\% of the patients), whilst ataxia and/or incoordination is detected in a far from negligible number of patients: $20-38 \%$ in several large series (Guidetti and Spallone 1980; Meyer et al. 1984). Deficits of the lower cranial nerves are infrequent except for cranial nerve IX involvement, which occurred in approximately $30 \%$ of our and in the Mayo Clinic' patients, and trigeminal sensory loss. Actually, due to their anatomical location, these structures are likely to be dislodged by masses passing through the foramen magnum. Single cases have been described 
of paresis of the motor branch of cranial nerve V (Shishikina and Kuvshinova 1961), and of onion-like trigeminal hypesthesia mimicking a demyelinating disease in a foramen magnum meningioma (Craig et al. 1956). Infrequent findings are the lhermitte sign, which may lead to an erroneous suspicion of multiple sclerosis, and features of the Bernard-Horner syndrome. The latter, usually incomplete, are slight ptosis and pupillary inequality (Stein et al. 1963). Papilledema was observed in less than $10 \%$ in ours as well as in the Mayo Clinic' patients. Arseni and Maretsis (1974) have tentatively explained the occurrence of papilledema in spinal neoplasm as a possible result of disturbances of the CSF circulation related to the increase in the total protein content of the spinal fluid. However, Meyer et al. (1984) have stated that the intracranial extension of tumors of the foramen magnum was a major factor in the pathogenesis of papilledema in their patients.

In conclusion, neurological signs in patients with these lesions are protean and often misleading. Clinical signs of long tracts involvement may closely resemble other surgical and nonsurgical diseases of the spinal cord. The presence of diagnostic neurological signs such as hypesthesia in the $\mathrm{C}_{2}$ territory, deficit of cranial nerve IX, pseudoastereognosis is not at all constant. Other signs such as atrophy of the intrinsic muscles of the hands and cape sensory loss may be misleading. So, diagnosis of tumor of the foramen magnum can be placed only occasionally on the clinical evidence.

\section{Ancillary Investigations}

\section{Neurophysiological Investigations}

Electroencephalography was performed in a few patients with foramen magnum tumors, and was usually noncontributory. Electromyography was performed in three of our patients, all of whom had atrophic changes in the intrinsic muscles of the hands. In two patients the EMG showed signs of denervation of these muscles, such as fibrillary action potentials in the $\mathrm{C}_{7}-\mathrm{T}_{1}$ radicular distribution. In the remaining case there were signs of upper motor neuron involvement.

Conflicting EMG results have been reported by Yasuoka et al. (1978) in their large series of patients with tumors of the foramen magnum. Previously there had been only a few reports on EMG findings in patients with atrophy of the hands and foramen magnum tumors (Cohen and McRae 1962; Liveson et al. 1973). EMG in these cases showed, as a rule, signs of anterior horn cell involvement at low cervical level. However, Yasuoka et al. (1978) concluded that there is not sufficient EMG evidence in the literature or in their own experience to substantiate the hypothesis 
that anterior horn cell involvement, possibly by a mechanism of vascular insufficiency, is the only explanation for the pathogenesis of atrophic changes of the hand muscles in patients with tumors of the foramen magnum.

We did not perform evoked potential studies in our patients, and we know of no one who has reported using them in patients with these lesions.

\section{Lumbar Puncture}

A lumbar puncture was performed in 21 of our 26 patients, as a rule during myelographic examination. Approximately half of the patients had either complete or partial block in the Queckenstedt test together with marked elevation of the total protein content (range 130-1100 mg\%), whilst 7 cases showed a normal manometric response with a usually moderate total protein elevation in the spinal fluid ranging from 40 to $130 \mathrm{mg} \%$ (average $83 \mathrm{mg} \%)$. In 5 patients (19\%) the results of CSF examination were unremarkable. A recent report from the Mayo Clinic (Meyer et al. 1984) claimed an even higher rate-approximately $50 \%$ - of negative CSF findings, but different results have been reported by others (Stein et al. 1963). It must be remembered, however, that other spinal lesions such as cervical spondylosis may occasionally (Brain et al. 1952; Guidetti 1958) increase the total protein content in the CSF, as pointed out by Stein et al. (1963). Because of this and the relative frequency of negative findings lumbar puncture is of secondary value in the diagnosis of benign tumors of the foramen magnum.

\section{Radiology}

\section{Plain Roentgenograms}

Plain X-ray evaluation of tumors of the foramen magnum included standard A-P and lateral views, the Towne basal projection and the oblique $35^{\circ}$ views for demonstrating the intervertebral foramina. Plain X-rays are usually the first radiological investigation performed in patients with these lesions, although they do not often suggest a mass at the foramen magnum. In our experience, the findings were positive in 12 cases $(46 \%)$, in half of which they consisted only in radiological signs of cervical spondylosis such as intervertebral space narrowing with osteophytosis. In 6 cases $(23 \%)$ the findings indicated a possible mass lesion, that is:

- Signs of pedicle and/or long erosion with enlargement of an intervertebral foramen - or increased $\mathrm{C}_{1}-\mathrm{C}_{2}$ interlaminar distance - which were present in four cases of hourglass neurinoma.

- A hyperostotic lesion located anterolaterally at the foramen magnum was shown in a case of meningioma. This finding was highly relevant to 
a correct diagnosis in this patient, who had been treated for multiple sclerosis for three years (Guidetti and Spallone 1980).

- Radiological signs of long-standing increased ICP were detected in a 26 year old woman with a spinocranial neurinoma, who presented clinically with almost nothing but signs of slowly progressing intracranial hypertension.

In conclusion, the diagnostic relevance of plain roentgenography in cases of foramen magnum tumors is secondary but by no means negligible. Actually, in our series as well as in the material of others (Hirano et al. 1983; Krenkel and Friedmann 1967; Lové and Adson 1941; Yasuoka et al. 1978) pedicle erosion and enlargement of an intervertebral foramen - or widening of the $\mathrm{C}_{1}-\mathrm{C}_{2}$ interlaminar distance - were relatively common findings in cases of spinocranial neurinoma. Positive plain X-ray findings in the presence of foramen magnum meningioma appear to be exceptional.

\section{Air Studies}

Metzger et al. (1971) have reported excellent results with air studies in the radiological diagnosis of tumors of the foramen magnum. Other authors (Tristan and Hodes 1958) had warned against their use in the presence of these lesions, due to the tendency for the air to pass posteriorly at the level of the foramen, so that an anterior mass might be missed. An air study was conducted in 4 of our cases, the last of which in 1976. This test demonstrated the lesion in three cases. An anterior meningioma was missed in the remaining patient. In all cases opaque myelography subsequently ensured better anatomical definition of the mass.

\section{Contrast Ventriculography}

Contrast ventriculography was performed early in our experience in three cases, whose main symptoms and signs were related to increased ICP (Fig. 1). This invasive test has subsequently been abandoned.

\section{Opaque Myelography}

It is generally agreed that myelography with contrast medium is the main diagnostic test when a foramen magnum mass is suspected.

The introduction of water-soluble contrast media (Scholten and Hekster 1977) has reduced the risk of short - and long - term complications related to this test. However tumors of the foramen magnum may escape myelographic demonstration (Howe and Taren 1973), partly because of the relative width of the subarachnoid spaces at the level of the cranio-cervical junction (Bull 1974; Du Boulay and McDonald 1964).

To avoid these potential diagnostic pitfalls, a high degree of technical accuracy is required when performing opaque myelography for a suspected 


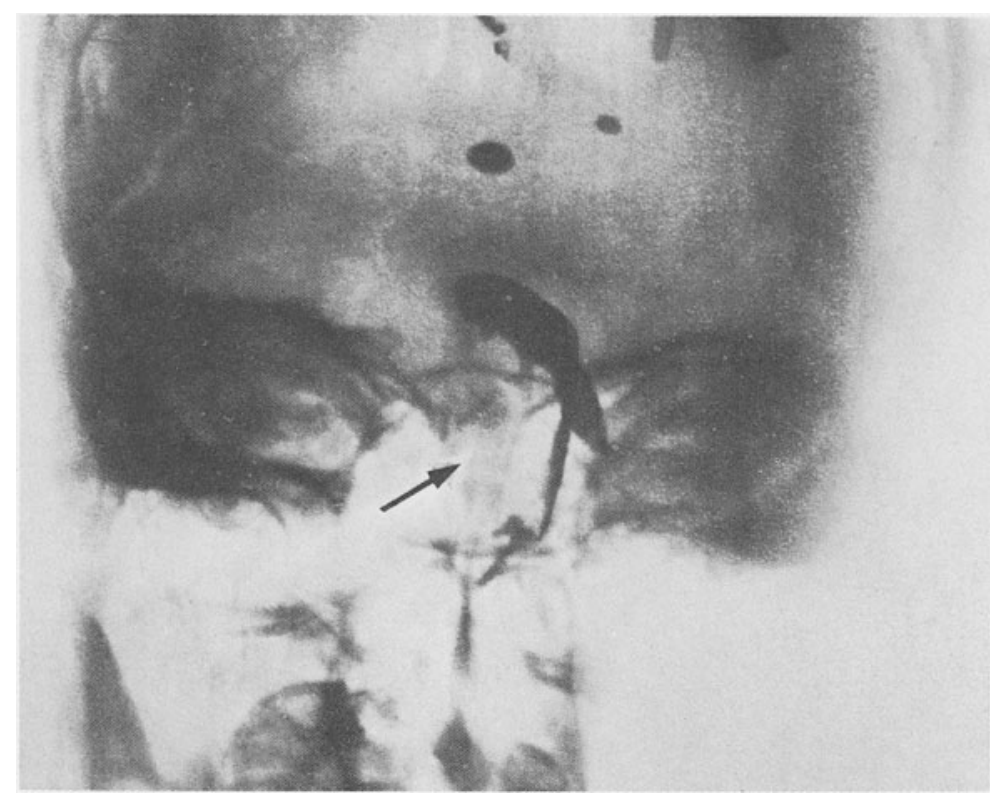

Fig. 1. Contrast ventriculography reveals a large mass (arrow) at the foramen magnum with posterolateral displacement of the cervicomedullary nervous structures

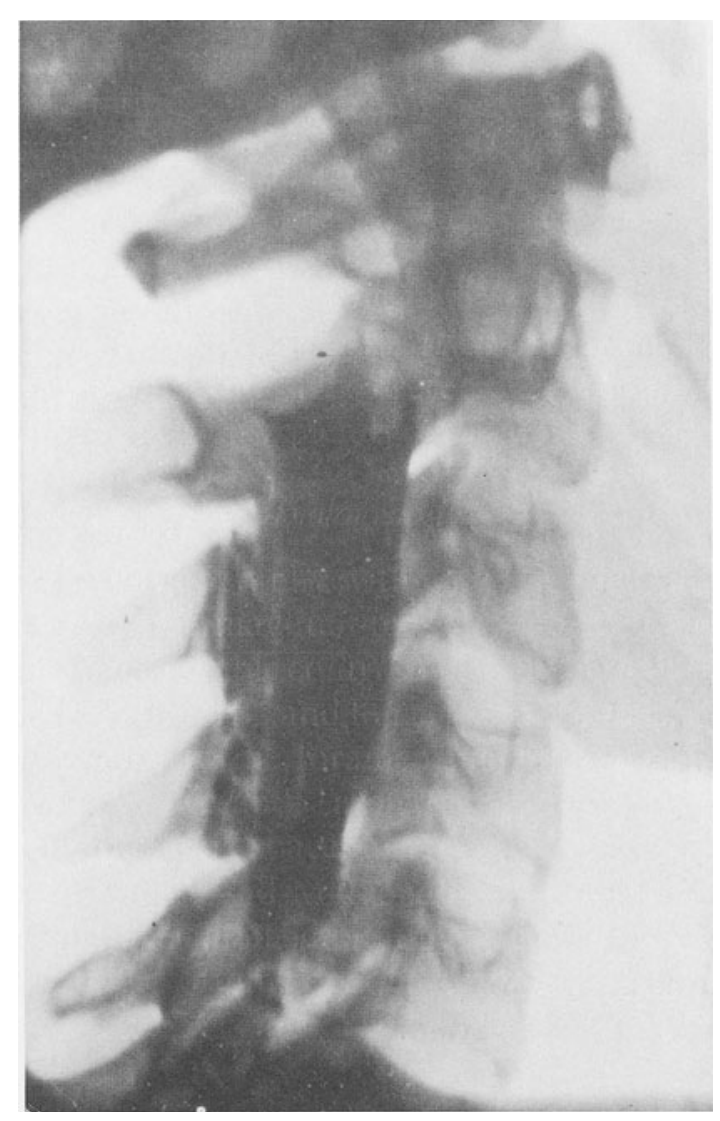

Fig. 2. Contrast myelography shows a total block at C.2 


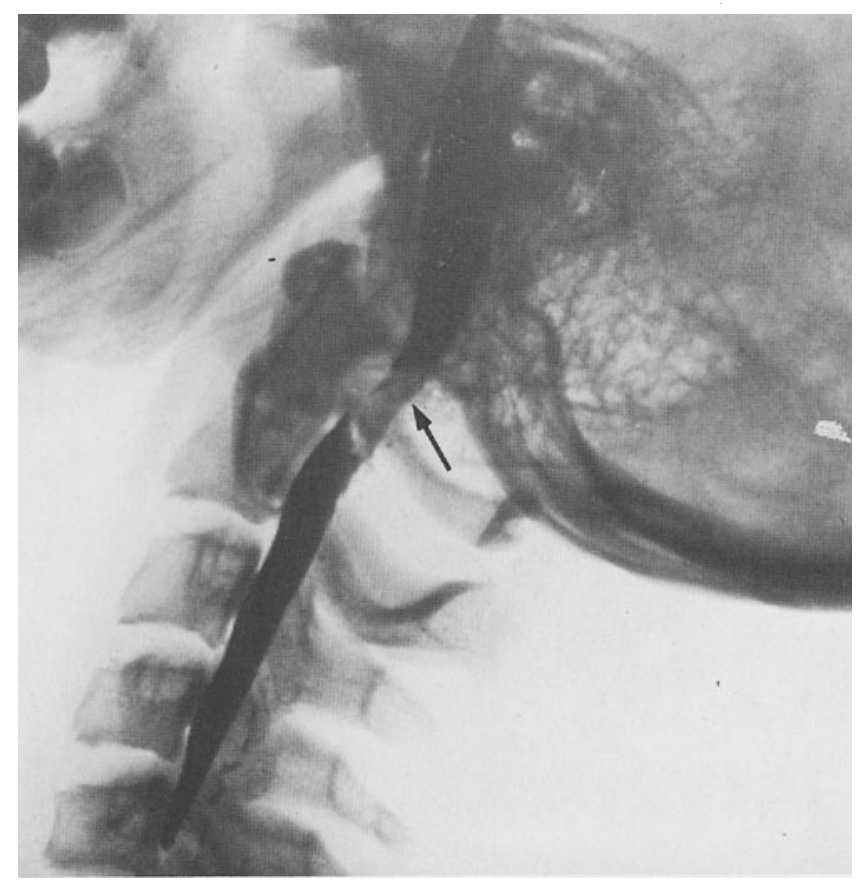

Fig. 3. Contrast myelography shows the anterior subarachnoid spaces interrupted by a mass (arrow)

foramen magnum tumor (Aring 1974; Du Boulay and McDonald 1964; Howe and Taren 1973). The contrast medium should be injected by lumbar puncture, in order to avoid the risk of injury to the displaced cord inherent in either a cisternal or a lateral high cervical puncture. In our experience around $9 \mathrm{cc}$ of contrast, or slightly more with the newly introduced metrizamide and Iopamidol, was sufficient for adequate imaging of the foramen magnum region. The anterior subarachnoid space must be visualized as far as the pontine cistern in doubtful cases (Malis 1958). In three of our patients who had undergone opaque myelography elsewhere the tumor was missed through inadequate demonstration of the foramen magnum region. The lateral inclination maneuver described by Margolis (1976) is also useful for decreasing the possibility of missing an anteriorly located mass. Myelography with the patient in the supine position has been advocated by some authors (Aring 1974; Bull 1974; Du Boulay and McDonald 1964) in doubtful cases, but it has never been necessary in our experience.

Opaque myelography was performed in 21 of our patient. This test has invariably offered convincing radiological demonstration of the tumor as well as an adequate indication of its site and size in most cases (Figs. 2 and 3). Meyer et al. (1984) state that myelography was diagnostic in $95 \%$ of the cases in their large series from the Mayo Clinic. 


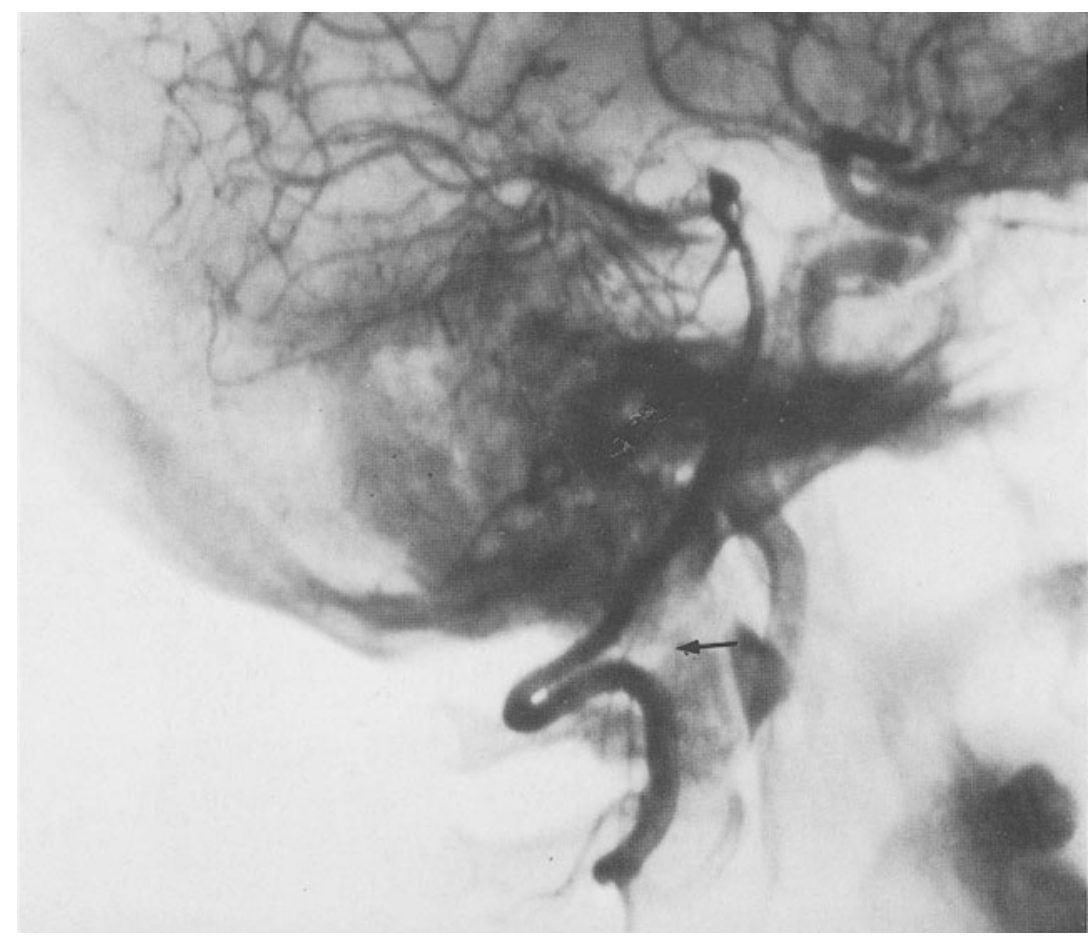

Fig. 4. Selective vertebral angiogram shows that the anterior spinal artery is displaced posteriorly (arrow)

\section{Angiography}

Angiography has become part of the radiological work-up on tumors of the foramen magnum only in recent years (Gabrielsen and Seeger 1973; Marc and Schechter 1975). We performed angiography in 10 of our cases. In all these patients the vertebral artery of the supposed side of the tumor was injected, and frequently the distal segment of the contralateral vertebral artery was also visualized.

In 8 cases one carotid artery was also studied. Carotid angiograms were not positive except in one case in which signs of hydrocephalus were present. Vertebral angiography was interpreted as normal in 2 of these 10 patients $(20 \%)$ early in our experience. In the remaining cases this examination invariably demonstrated abnormalities, namely PICA displacement (3 cases), anterior spinal artery displacement (4 cases) (Fig. 4) vertebral artery displacement ( 2 cases) (Fig. 5 A, B), posterior meningeal artery hypertrophy (1 case) (Fig. 6), and vascular blush (3 case). Hypertrophy of the posterior meningeal artery and blush occurred only in cases of meningioma. Table 8 summarizes the angiographic findings in our patients. As stated by Ga- 


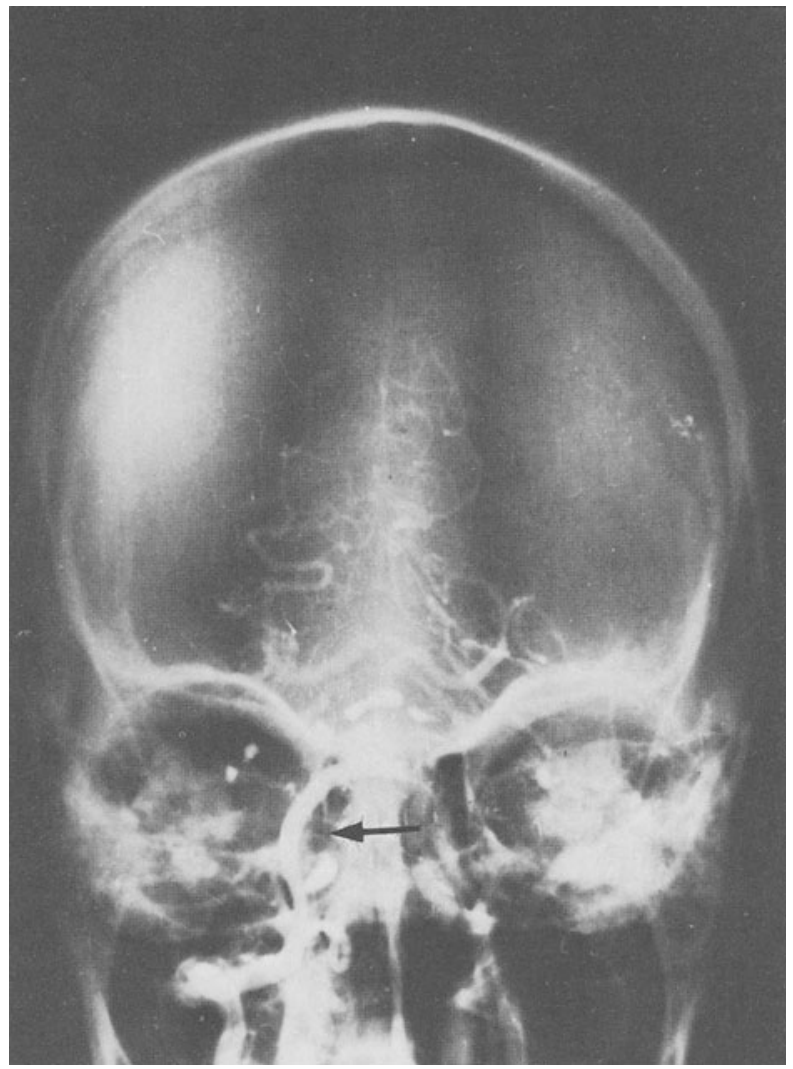

A

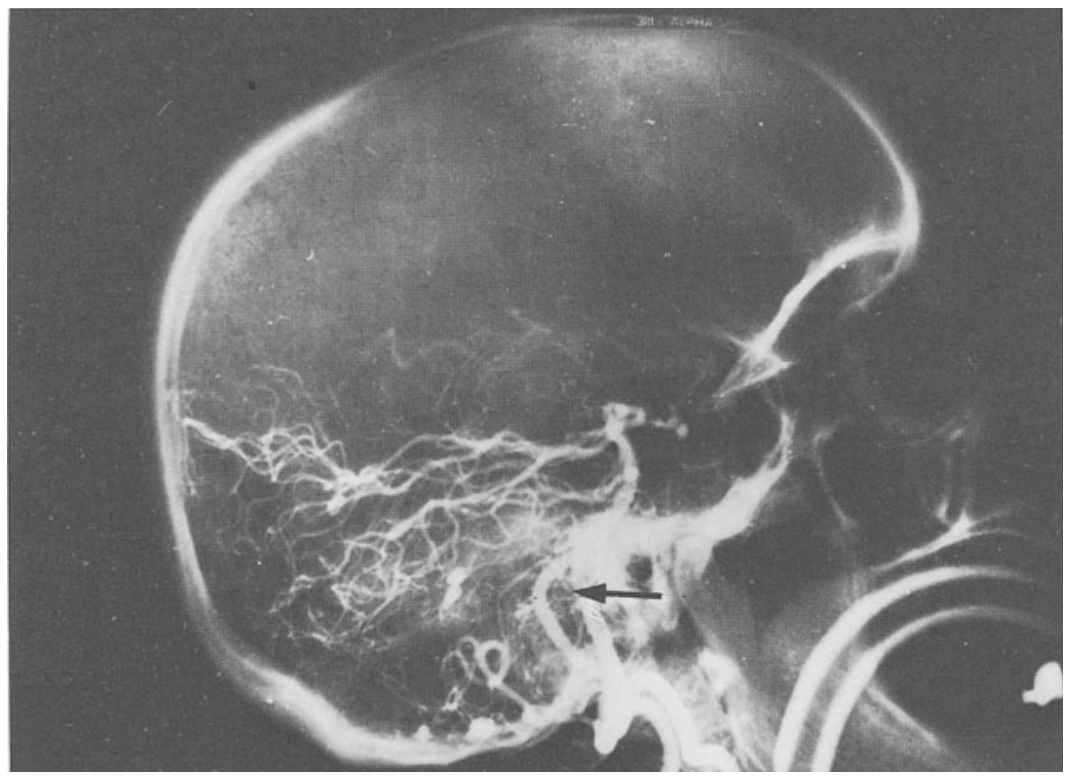

B

Figs. 5 A and B. Selective vertebral angiogram shows that the vertebrobasilar arteries are displaced laterally and posteriorly (arrow) 


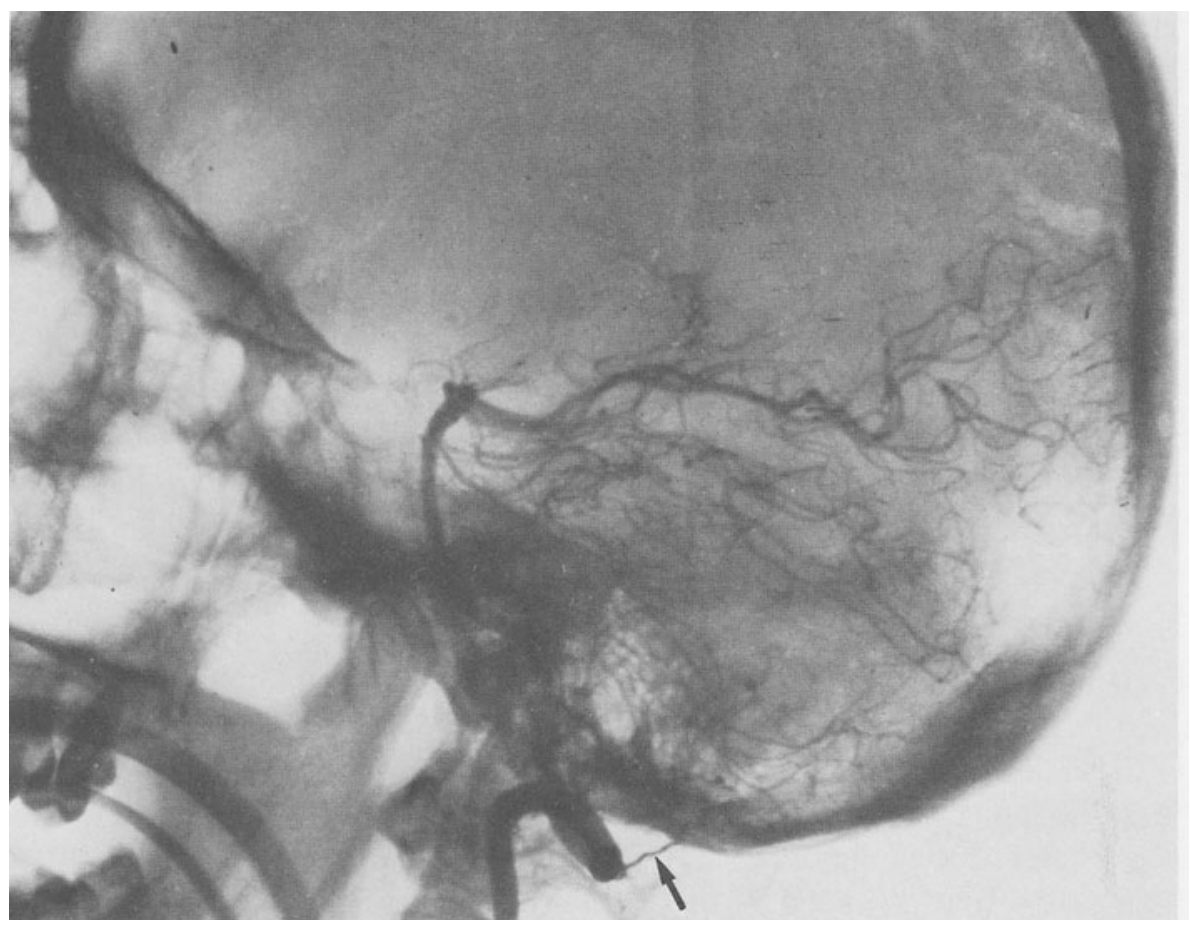

Fig. 6. Selective vertebral angiogram reveals hypertrophy of the posterior meningeal artery supplying the meningiomas (arrow)

Table 8. Angiographic Findings in Our Patients

\begin{tabular}{lcl}
\hline Type of angiography & $\begin{array}{l}\text { N. of } \\
\text { patients }\end{array}$ & Findings \\
\hline Carotid angiography & 8 & No abnormality* \\
& & 2 no abnormality \\
& 3 PICA displacement \\
& 4 ASA displacement \\
& 2 VA displacement \\
& 1 post. mening. art. \\
& hypertrophy** \\
& 3 vascular blush $* *$ \\
\hline
\end{tabular}

* One case showed angiographic features of hydrocephalus.

** Meningioma.

PICA: posterior inferior cerebellar artery. ASA: anterior spinal artery. VA: vertebral artery. 
brielsen and Seeger (1973), prerequisites for vertebral angiography to be diagnostic in tumors of the foramen magnum are optimal technique, and good quality radiological pictures, including subtraction views when required. Recent reports from Mayo Clinic groups (Meyer et al. 1984; Yasuoka et al. 1978) suggest the role of angiography in the management of tumors of the foramen magnum should be limited. We feel that angiography may delineate the degree of vascular involvement by the tumor, when this is to be expected, such as in the presence of large lesions, and this might be helpful in surgical planning. In one of our cases, reported previously in detail, angiography showed displacement and segmental narrowing of one vertebral artery, suggesting vessel encasement by the tumor (Spallone et al. 1980).

\section{Computed Tomography}

The first paper on the CT diagnosis of benign extramedullary tumors of the foramen magnum was published by us in 1980 (Spallone et al.). It dealth with the first two of our patients who underwent CT scanning. In both cases - a neurinoma and craniospinal meningioma, both located anteriorly - this test was diagnostic, and offered clues for possible preoperative diagnosis of nature, such as mode of contrast enhancement, presence of signs of bony erosion, shape and homogeneity of the mass. Subsequent experience with a completely thrombosed giant basilar aneurysm mimicking a foramen magnum tumor, which was diagnosed by CT scan (Spallone 1982) seemed to point to computed tomography as the main diagnostic test for tumors of the foramen magnum. However more recent cases have not altogether borne out our previous expectations. In fact, CT demonstrated the lesion in three subsequent cases (Fig. 7) but not in a case of intradural spinocranial neurinoma despite contrast enhancement with a third generation scanner. This gives a diagnostic accuracy of approximately $75 \%$, which matches the recent experience of the Mayo Clinic (Meyer et al. 1984). Intraspinal injection of contrast may obviously offer excellent delineation of the mass at CT (Vancoillie and Veiga-Pires 1979; Hirata et al. 1985 ) but this makes this test as invasive as myelography.

\section{Nuclear Magnetic Resonance}

On recent evidence NMR is becoming the procedure of choice in the diagnosis of diseases of the spine. Although demonstrations of foramen magnum tumors shown by NMR are still few (Crockard 1985), some authors (Meyer et al. 1984) have stated that this test is becoming the procedure of choice for lesions of the foramen magnum. NMR was performed in one of our cases (Fig. 8), in which it demonstrated the lesion so beautifully 


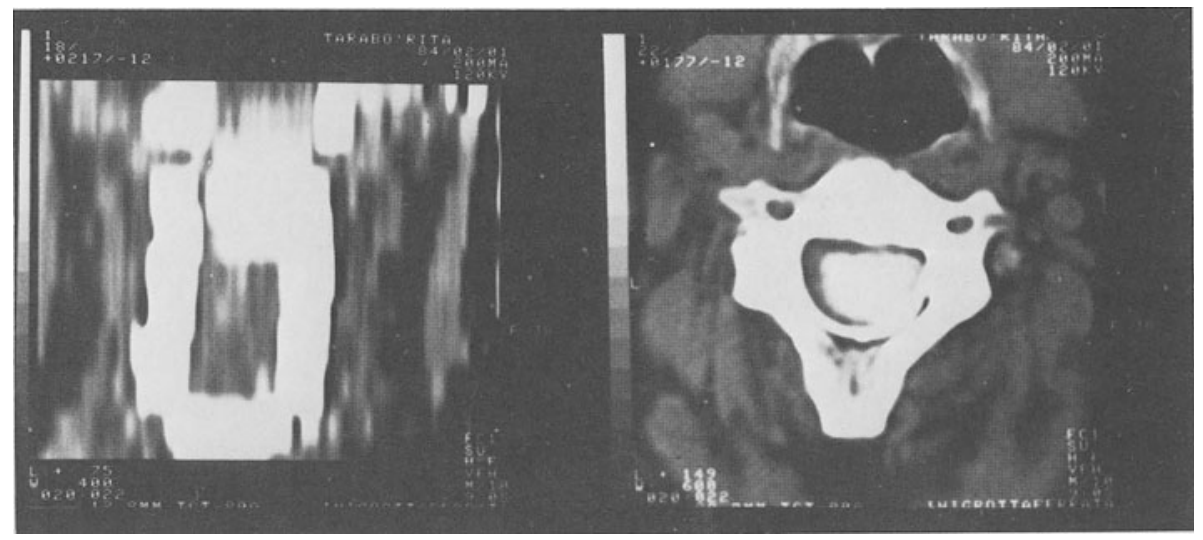

Fig. 7. CT scan reveals a large enhancing meningioma of the foramen magnum

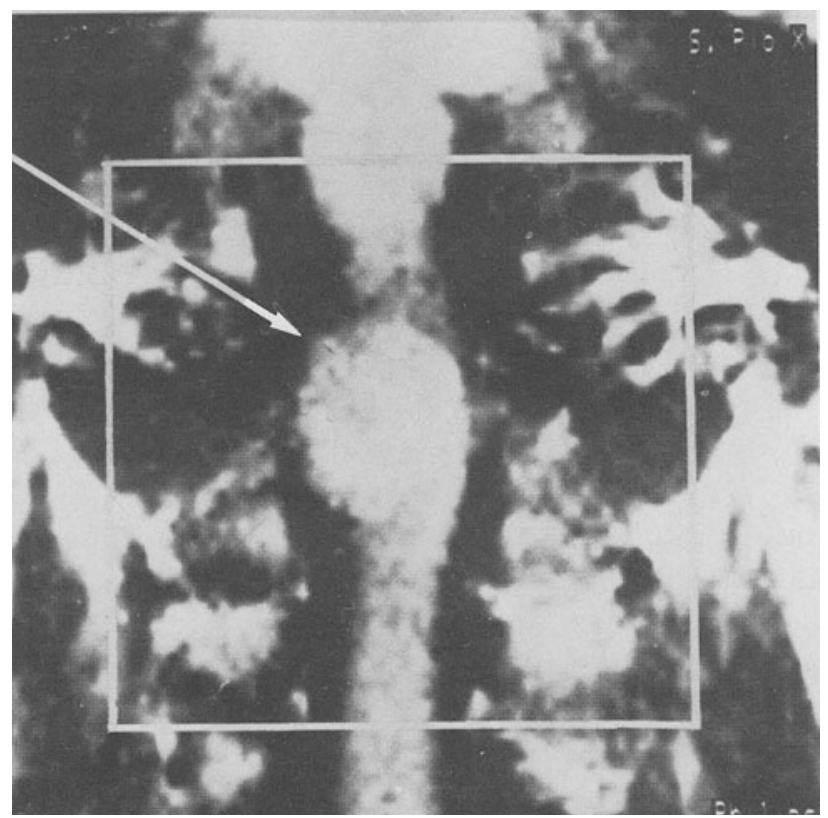

Fig. 8. MNR shows a hyperdense tumor of the foramen magnum (arrow)

that other tests were unnecessary. Accordingly, we too are inclined to think that NMR will replace other, more invasive, diagnostic tools for tumors of the foramen magnum, and it appears to be superior to CT scan in the diagnosis of these lesions. CT scanning might remain important for the preoperative diagnosis of nature. 


\section{Operative Management}

In benign tumors of the foramen magnum the aim of surgery is radical removal of the tumor and of any infiltrated dura mater and bone. However, total removal of a bulky meningioma, especially if it arises from the anterior margin of the foramen magnum, carries risks that have to be closely assessed by the surgeon and discussed with the patient. The first condition for a satisfactory outcome is careful preparation of the patient for the operation, care being taken to detect and correct any malfunction of other organs or system. In patients with tumors of the posterior cranial fossa the degree of tolerance to bending of the head should be evaluated beforehand in order to position it correctly on the operating table and avoid marked flexion of the neck which may occasion impairment of nervous structures. Dexamethasone in a dose of $12 \mathrm{mg}$ should be given for three days before the operation and for three days after it, but no antibiotics are routinely used.

\section{Operative Approach}

The posterior midline approach proved appropriate in all our patients except one, who had already undergone surgery by posterior approach elsewhere; in this case the meningioma was removed by transcervicaltransclival approach. We prefer this more complex route to the transoral approach, which has the disadvantage of crossing a contaminated field and which in the case of removal of dura mater, necessary in meningiomas, increases the risk of a cerebrospinal fistula and meningitis. This preference is supported by the fact that we have been able to find only two published cases in which the transoral route was used for intradural tumors. The first, a sarcoma removed partially, was described by Mullan et al. in 1966 and the second, a neurinoma, was described by Crockard and Bradford in 1985. From what has been reported we agree with Pásztor and others who consider the transoral approach suitable only for extradural diseases of the structures constituting the craniovertebral junction. For information on this approach we refer the reader to the description by Pasztor in Vol. 12 of this series (recently Miller and Crockard reported two cases transoral subtotal removal of foramen magnum meningioma. Cerebrospinal fluid fistula was avoided by dural repair using a thrombin glue and long term CSF diversion).

\section{Anesthesia}

The classic principles of neurosurgical anesthesia apply also to tumors of the foramen magnum. General anesthesia with positive pressure ventilation and orotracheal intubation is the rule. Orotracheal intubation is preferred in these patients because it is tolerated better in cases in which the endo- 
tracheal tube has to be kept in situ postoperatively until the patient is fully conscious and breathing normally.

The practice of relying on spontaneous respiration, common at one time, for the detection of any signs of nervous system impairment, was abandoned years ago when it was realized that the onset of cardiocirculatory problems (arrhythmias, bradycardia or tachycardia, a fall or sudden rise in blood pressure) precedes breathing problems, requiring a halt in the operation and prompting increased gentleness in surgical maneuvers. Further valuable information is supplied by an analysis of the somatosensory evoked potentials recorded during the operation.

In patients operated on in the half-sitting position it is advisable to place the blood pressure transducer at the level of the head so that actual intracranial arterial pressure values are known. Venous pressure is monitored by means of a catheter inserted via the brachial vein into the right atrium. This catheter can also be used, if necessary, for aspirating any air emboli evidenced by clinical and EKG signs and by the signals transmitted by ultrasound doppler placed on the chest at heart level. In our experience of over 1.000 patients operated on in the halfseated position we have never encountered air emboli that called for therapeutic measures. We attribute this fortunate record to an obsessive concern with spreading hemostatic wax on the bony margins as soon as they are exposed, constantly spraying the operative field with warm physiologic saline, never opening the venous sinuses unless they have been sealed off, and lastly never using high frequency ventilation in these patients.

\section{Positioning (Figs. 9 A and B)}

It is the surgeon's responsibility to see for himself that the patient is properly positioned on the operating table. Correct positioning facilitates and speeds the operation. An incorrect position complicates the surgical maneuvers and lengthens the operation. There is no ideal position for patients with tumors of the posterior cranial fossa. The half-seated position reduces bleeding, facilitates respiration and venous return and affords an almost dry operative field. But it has disadvantages: the possibility of a sudden fall in blood pressure, a very serious occurrence in debilitated elderly patients; appearance of an air embolus; and the fact that the use of the operating microscope in this position is more fatiguing for the surgeon, who in addition cannot make full use of the help of a coworker. Most of our patients were operated on in the half-sitting position but in the past few years we have found the lateral dorsal position satisfactory. Whatever the chosen position, which we decide according to the patient's age and state of health and to the tumor site, the head is fixed, in slight flexion, in a Mayfield headrest, anchored to the operating table. The lower limbs, 


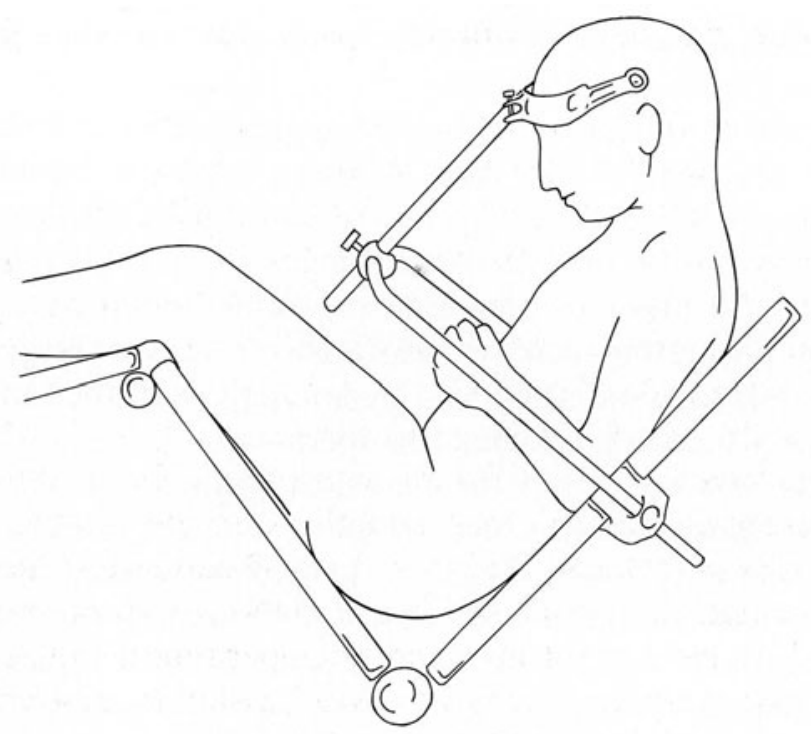

Fig. 9 A. Drawing showing half-sitting position

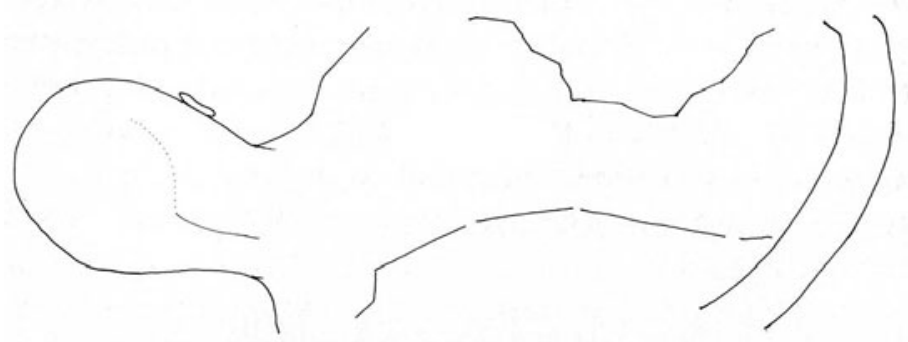

Fig. 9 B. Drawing showing the lateral dorsal position. Medial incision is extended obliquely upward in tumors extending to the cerebellopontine angle (dotted line)

bound with elastic bandage, are placed together semiflexed, in order to avoid lumbar and sciatic pain in the postoperative period, while the upper limbs are semiflexed and supported.

If the dorsal position is chosen, the patient is placed on the table in the lateral position with the head slightly bent and rotated $25^{\circ}$ and raised slightly above heart level. In this position the cerebellum falls by force of gravity to the opposite side, thereby giving the surgeon more room in which to maneuver. This position has proved especially helpful in the case of large tumors arising from the anterior margin of the foramen magnum.

\section{Technique}

The surgical approach must be decided upon beforehand, on the basis of tumor site, type and size. As all but one of our patients were operated on 
either by midline or midlateral suboccipital approach, we shall focus mainly on this route.

Having ascertained that the patient is correctly positioned on the operating table, the surgeon uses a knife tip to mark out the access route, which is then generously infiltrated with novocaine-epinephrine. The operating field is covered with sterile towels and a burrhole drilled $7 \mathrm{~cm}$ above the external occipital protuberance and $3 \mathrm{~cm}$ from the midline. An incision is made in the dura mater and a silicon catheter is inserted through the burrhole as far as the foramen of Monro. If the cerebrospinal fluid pressure is high, CSF is drawn off, drop by drop, in order to prevent ventricular collapse and formation of a subdural hematoma. The other end of the catheter is placed in a sterile bag and the CSF pressure is monitored continuously. The catheter is kept in situ for 24-48 hours and then removed. In only one patient, who developed hydrocephalus some months after the operation, did we have to set up a ventriculoperitoneal shunt.

The next step in the operation is a skin incision from $4 \mathrm{~cm}$ above the inion to cervical vertebra 5. In patients in whom the tumor extends toward the cerebellopontine angle or arises from the anterior margin of the foramen magnum the skin incision is extended from $2 \mathrm{~cm}$ below the inion into the mastoid region. The skin is retracted and a Y-shaped incision made in the fascia, likewise retracted. The incision continues, practically bloodless, remaining strictly on the median raphe. The muscles and aponeuroses on the occipital squama and the spinous processes and are freed with electric knife and periosteal elevator. After retraction of the muscles, two drillholes are made aside the median sinus, care being taken not to damage it. The occipital squama, spinous processes and transverse processes are removed with a Leksell rongeur and the atlas with a Kerrison rongeur by subperiosteal route. If a venous sinus is accidentally damaged, it is sutured with fine needles or covered with Surgicel or muscle (Figs. $10 \mathrm{~A}$ and B).

If the meningioma is inserted on the anterior dura mater of the foramen magnum, it is advisable to remove the posterior portion of the joint facets of the atlas and occipital bone with an electric drill and diamond burr. In carrying out this maneuver, under the operating microscope, the surgeon must take extreme care not to damage the vertebral artery, which runs in a deep bony groove in contact with the atlantooccipital joint capsule immediately behind the lateral mass of the atlas. Bleeding from the venous plexus, which accompanies the vertebral artery before perforating the dura mater, is arrested by bipolar coagulation or Surgicel. The removal of a portion of the joint facets affords lateral access to the tumor, which avoids damaging compression of the nervous tissue. If the tumor develops into the cerebellopontine angle, the craniectomy must be extended as far as the retromastoid region (Fig. 11).

Having covered the musculocutaneous margins with pledgets soaked in 


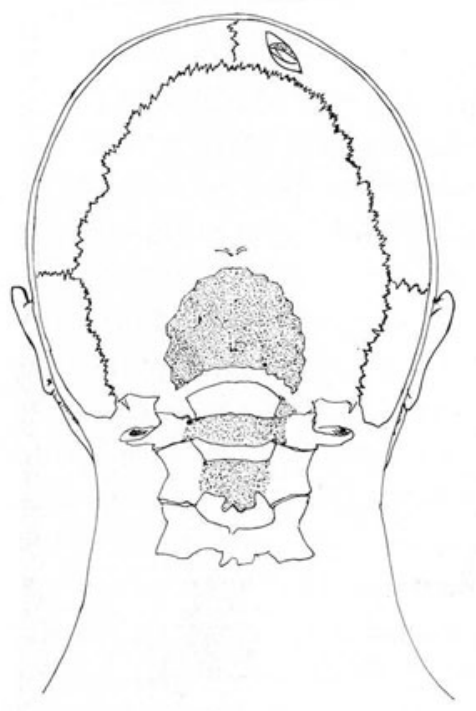

A

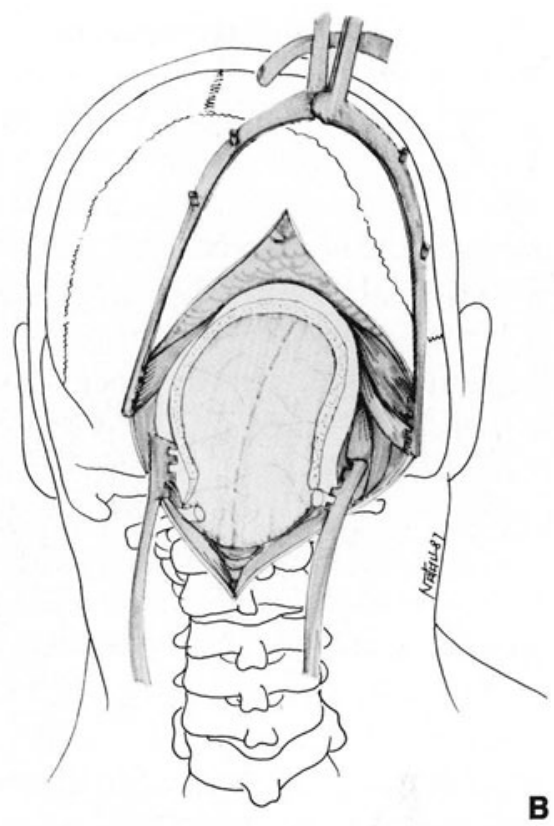

Fig. 10 A. A shaded area indicates size of craniotomy and laminectomy

Fig. 10 B. Drawing showing craniectomy, laminectomy and dural incision

physiologic saline, the surgeon makes a $\mathrm{Y}$ incision in the dura mater and retracts its margins with stay sutures. In patients in whom the tumor extends into the cerebellopontine angle he opens the dura obliquely upward as far as the junction between the transverse sinus and the sigmoid sinus. In incising the dura it is wise to section the venous sinuses between two silver clips or ligatures. If the dura has been opened correctly, the underlying arachnoid will be found to be intact. The arachnoid is opened and separated as far as necessary. On introducing the microscope or loupe into the operating field, one can discern the site, size and nature of the tumor and its relationships with the surrounding structures. When the tumor has been located, the surrounding subarachnoid spaces are occluded with sponges soaked in physiologic saline to prevent the spread of blood and tumor fragments.

The great majority of subdural tumors of the foramen magnum lie laterally or anterolaterally, displacing the nervous structures dorsolaterally. In cases in which the meningioma is situated anteriorly the medulla oblongata and high cervical cord are pushed backward and cover the tumor, giving the impression to an inexperienced eye that the tumor is intra-axial. This mistake must be more frequent than is thought, considering that we had to reoperate on as many as two patients in whom the diagnosis at first operation had been intra-axial tumor. 


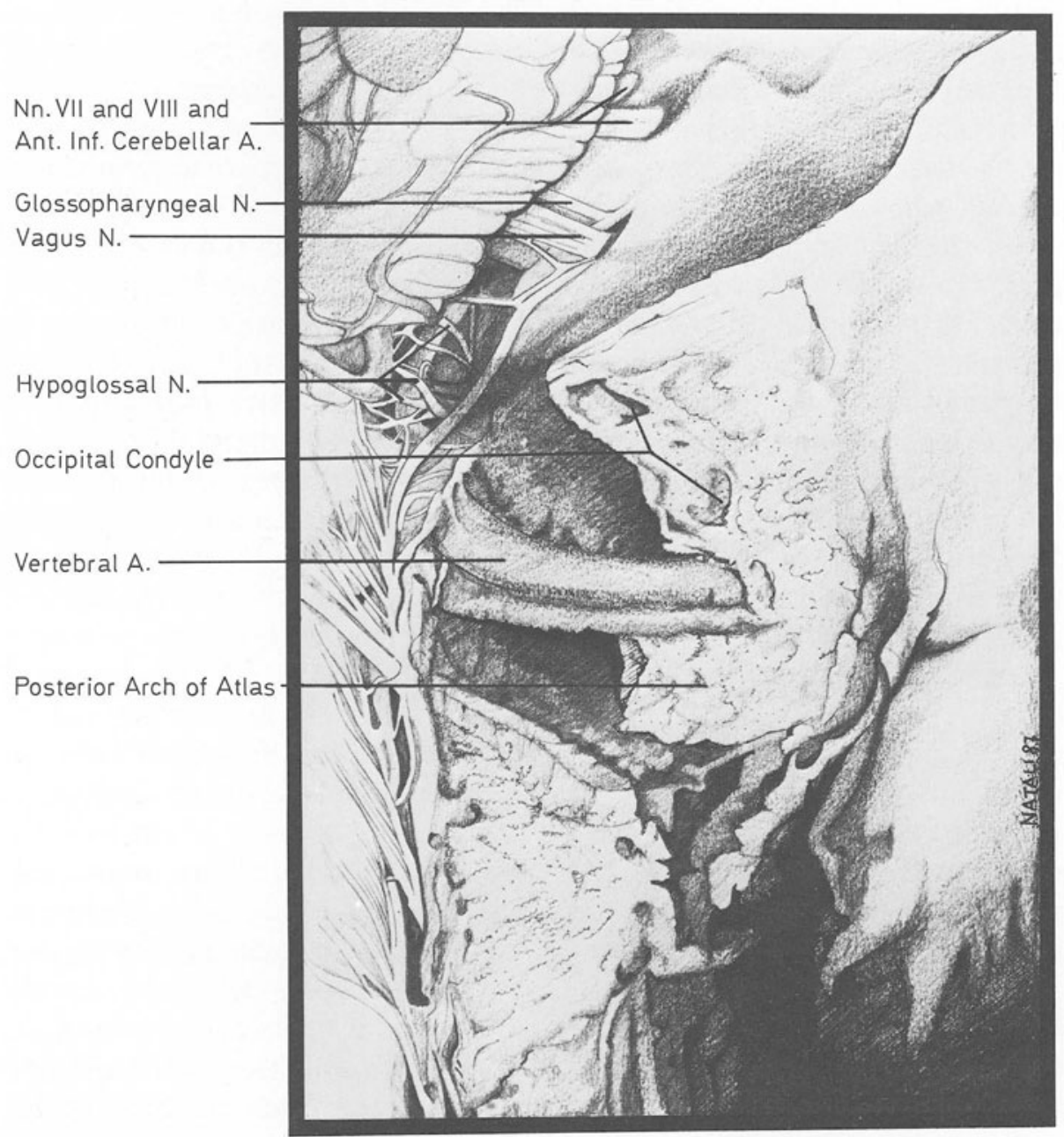

Fig. 11. Craniocervical junction. Subarachnoid space of right posterior fossa and vertebral canal. Removal of the foramen magnum is carried out laterally to include part of the occipital condyle and part of condyle of atlas. Cerebellum is displaced to the left

In the case of anterolateral tumors the dentate ligament, the roots of $\mathrm{C}_{1}-\mathrm{C}_{2}$ and part of those of the spinal accessory nerve appear to the surgeon to be stretched and pushed backward. Having sectioned the dentate ligament as laterally as possible together with the roots of $C_{1}-C_{2}$, he separates those of the spinal accessory nerve gently from the tumor capsule, displaces them upward and protects them with a sponge. Raising the ipsilateral tonsil and the lower portion of the cerebellum with a spatula, he then gently rotates the spinal cord toward the opposite side, exerting gentle traction 
on the dentate ligament. As a rule, the whole of the tumor then appears and sponges are placed between the tumor capsule and nervous tissue. If the tumor is large or situated anteriorly it is helpful to section two or more dentate ligaments and the ipsilateral and contralateral roots in order to mobilize the cord more freely. Care must be taken to spare any radicular arteries when sectioning the nerve roots.

In the case of a small neurinoma block removal is possible without injury to the nervous tissue. If the neuroma is large the best course is to evacuate the contents after cautery and incision of its capsule. An ultrasonic aspirator is very useful for this purpose as it ensure rapid evacuation of the tumor contents without damage to neighboring tissues. In neurinomas that extend into an intervertebral foramen the foramen should be generously opened and, with the intracanalicular stump under traction, the root cut in healthy tissue. Sometimes it is best to remove the intrathecal portion first, sectioning it at the level of the foramen, and then the intracanalicular portion. If the extrathecal mass is large, it should be removed by anterior cervical approach at a later stage. The rare meningiomas with posterior attachment are removed with ease by sectioning the dura mater, after cauterizing it with a bipolar coagulator, around the base of the tumor attachment. In the case of an anterolateral insertion the tumor capsule, released from the anchorage of the dentate ligament, roots of $\mathrm{C}_{1}-\mathrm{C}_{2}$ and spinal accessory nerve, is coagulated and incised. In none of our patients did we succeed, without damaging the nervous tissue, in reducing the supply of blood to the tumor by sectioning first the dural insertion of the tumor in order to interrupt the blood flow from the posterior meningeal, occipital and sometimes the ascending pharyngeal arteries. After the tumor capsule has been incised, the tumor is emptied piecemeal of its contents using a sharp spoon, bipolar coagulation and Olivecrona scissors. Once the tumor has been emptied, the capsule is gently separated from the neighboring tissues and removed piecemeal. In these maneuvers the surgeon must always bear in mind the course of the underlying vertebral artery in order not to injure it (Figs. 12 A and B).

In the case of large meningiomas, especially those with insertion on the anterior margin of the foramen magnum, it is useful to remove part of the atlantooccipital joint facets, and in those developing toward the cerebellopontine angle the portion of the occipital squama that extends as far as the mastoid process. After evacuation of the tumor content, gentle traction is exerted on the capsule to separate it from neighboring vascular and nervous structures. In this maneuver the surgeon must distinguish the vessels and nerves that run around the tumor and are only displaced and stretched from those that are embedded in the tumor. In the first situation the vessels and nerves must be gently separated and protected with sponges. The small arteries that supply the tumor must be identified, not stretched, 


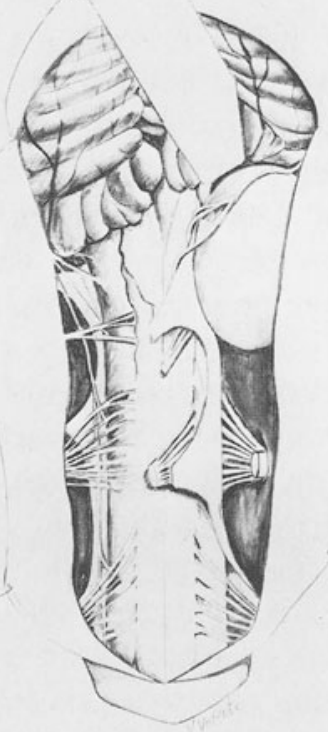

A

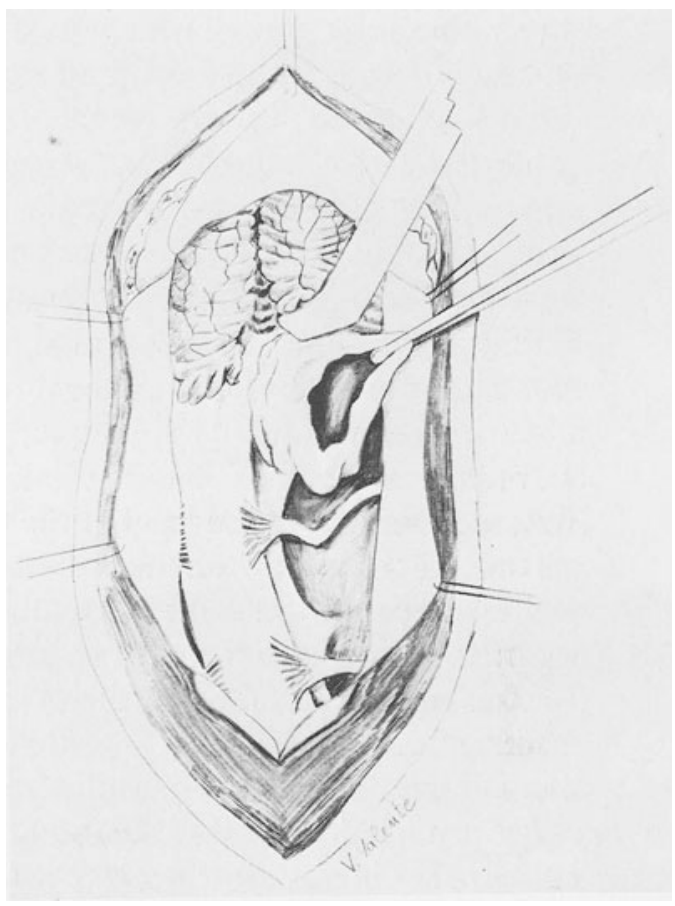

Fig. 12 A. Drawing showing foramen magnum meningiomas ventrolateral to the spinomedullary junction. The ipsilateral tonsil is raised and the dorsal roots and dentate ligaments sectioned. The spinal accessory nerve is gently separated from the tumor capsule and displaced upward

Fig. 12 B. As the capsule is collapsed, adhesion are dissected using microdissectors and bipolar coagulation. The capsula is gently separated from neighboring tissue and removed

in order not to tear them from their base of insertion, and then coagulated and sectioned flush with the tumor. In this first situation the tumor can be radically removed. In cases in which the nerves and vessels are embedded in the tumor, the tumor can be slit, under the microscope at high magnification, and removed around the arteries and nerves, but often in these cases it is wise to leave a thin layer of tumor attached to the arteries and nerves and rely on gentle coagulation of the residue. In these maneuvers the surgeon must establish a close working relationship with the anesthetist and the neurophysiologist who monitors the evoked potentials, and halt the operation momentarily if the nervous structures signal distress. After 
removal of the tumor the infiltrated dura mater must be removed as far as possible and the remainder throughly cauterized with a bipolar coagulator. Rigorous hemostasis is followed by the Valsalva maneuver to show up any bleeding points, which must be further coagulated. If the operation is straightfoward, the dura mater can be closed with interrupted sutures; otherwise it is left open with the marginstacked back. The dural defect is protected with a suitable dural substitute, or fascia lata. The patient is then wheeled to his bed and placed with his head at an angle of $30^{\circ}$. The orotracheal tube is not removed until the patient is perfectly lucid and his breathing strong. The pulse, blood pressure, temperature, breathing and CSF pressure must be monitored. The ventricular catheter is usually removed after 24-48 hours.

\section{Transcervical Transclival Approach}

We used this route of access in only one patient with a meningioma inserted on the anterior dura of the foramen magnum, which had been partially removed at another hospital by suboccipital approach. The approach used was the one described by Stevenson et al. in 1966 with slight variation.

The patient is placed on the operating table in the supine position with the head rotated about $25^{\circ}$ to the left and hyperextended in order to increase the submandibular and peripharyngeal spaces. General anesthesia is induced by nasotracheal intubation, which allows the mouth to be tightly closed. To widen the retropharyngeal space we use the maneuver described by Fry and Fry in 1980 and used in traumatic lesions of the extracranial ICA, which allows forward dislocation of the mandibular condyle. (In practical terms, the ipsilateral condyle is dislocated by inserting the index and middle finger into the buccal cavity and gripping the mandible between them and the thumb outside. With repeated traction on the mandible, while the thumb of the other hand exerts compression on the condyle in the same direction, the articulation eventually works loose. A more vigorous pull dislocates the condyle anteriorly. The maneuver is facilitated by the administration of curare.) This done, an incision is made in the skin from the mastoid process to the mandibular angle, thereafter curving along the anterior margin of the sternocleidomastoid muscle. After incision of the platysma and section of the external jugular vein, the superficial cervical and temporomandibular fasciae are incised. The carotid sheath is opened, the neurovascular bundle is moved gently to one side and the parotid gland is displaced medially and upward until the facial nerve, digastric muscle and hypoglossal nerve are exposed. After section of the posterior belly of the digastric muscle at the level of the intermediate tendon and superior thyroid and lingual arteries, the hypoglossal nerve is isolated and displaced downward. Then follows section of the stylohyoid muscle, which runs parallel to the digastric muscle, and of the stylomandibular ligament. If 


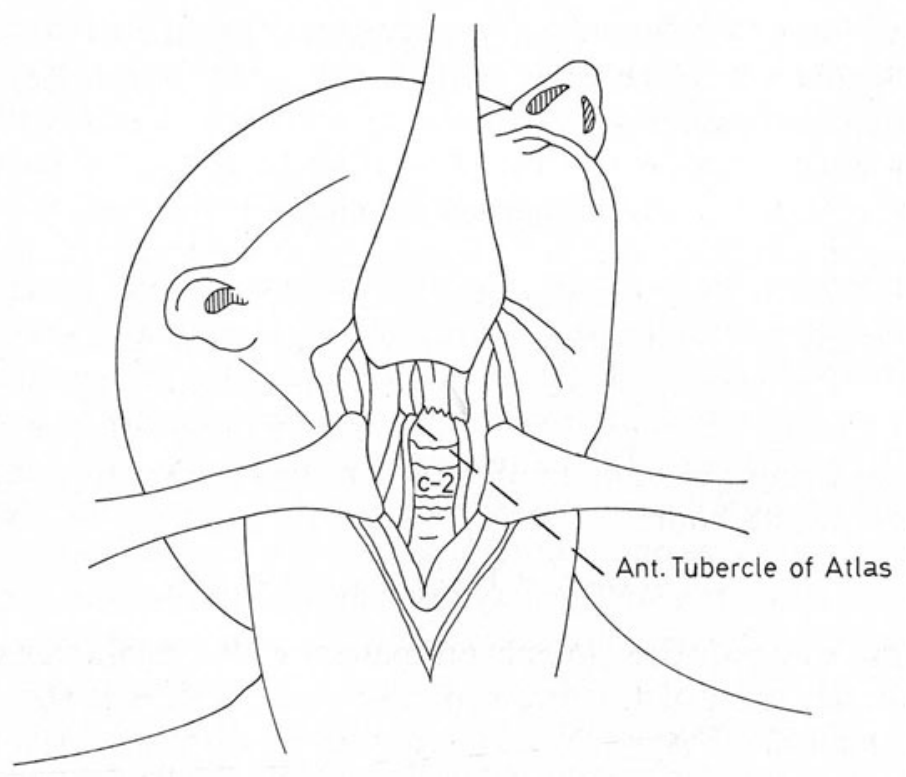

Fig. 13. Drawing showing retraction necessary to achieve exposure of the arch of atlas

the styloid process is too long and obstructs vision, it is partially fractured. Section of the stylopharyngeal bundle and of the one that extends from the epipharyngeal fascia to the prevertebral fascia reveals loose connective tissue, which allows easy blunt separation of the prevertebral from the pharyngeal fascia as far up as the pharyngeal tubercle, lying about $2 \mathrm{~cm}$ from the foramen magnum. After upward and medial displacement of the nasopharynx with a deep bladed retractor, the prevertebral fascia is incised longitudinally from the foramen magnum to $C_{3}$ and the neck muscles are separated subperiosteally and retracted laterally. With the microscope shifted into the operating field, an electric microdrill fitted with diamond burr is used to displace the atlas $8-10 \mathrm{~mm}$ to the right and left of the midline. Drilled at its base with a microdrill, the odontoid peg is removed, after section of the alar and apical ligaments. The lower portion of the clivus is then removed by microdrill and undercutting forceps, care being taken not to damage the inferior petrosal sinus and hypoglossal nerve. The tectorial membrane and posterior longitudinal ligament are incised to disclose the tumor infiltrated dura mater, which is cauterized with a bipolar coagulator and incised. The tumor is removed piecemeal with bipolar forceps and scissors on the same principle as for the suboccipital approach. After meticulous hemostasis, the residual cavity is filled with abdominal fat graft and Tissucol*. The muscles and prevertebral fascia are sutured

\footnotetext{
* Tissucol Oesterreichisches Institut fuer Haemoderivate Ges. M.B.H. Vienna.
} 
and likewise the other musculocutaneous layers. To prevent the formation of a CSF fistula, CSF drainage is set up for 48 hours by means of a lumbar subarachnoid catheter (Fig. 13).

\section{Postoperative Care}

Patients operated on in the sitting position are kept in the half-sitting position postoperatively, with no less than $30^{\circ}$ elevation of the head. The surgical drains are removed as a rule 24-48 hours after the operation. Vital signs must be carefully monitored during the first three postoperative days. This applies particularly to the respiratory parameters. We lost one patient - whose clinical details will be given in the following section - due to sudden onset of apnoea on the third postoperative day. For mild respiratory irregularities analeptics and/or oxygen may be sufficient but intubation and mechanical assistance may be warranted in some cases. Blood pressure should also carefully controlled, since there is a confirming risk of hypotension in patients maintained in the half-sitting position. Obviously any change in the postoperative neurological status should prompt appropriate measures to exclude the possibility of a postoperative epidural clot. Steroids, which are started 48 hours before surgery, are continued for three days following the operation and then gradually tapered off. We routinely give gastroprotective medication during steroid treatment, in order to minimize the known risk of gastrointestinal complications. Finally early physiotherapy will shorten the time required for neurological recovery and hasten neurological recovery even in patients with advanced symptoms.

\section{Clinical Results}

Total mortality related to the surgical procedure was $11 \%$ ( 3 out 26 cases). A 57 year old woman, the second patient in our series of tumors of the foramen magnum, was operated on for $4 \times 4 \mathrm{~cm}$ anterior craniospinal meningioma. Eight months before she had undergone elsewhere a high cervical laminectomy with intradural exploration, at which a bulging cord had been observed and an intramedullary tumor diagnosed. This only halted the progression of symptoms, which prompted revaluation of the case and reoperation by ourselves. Surgery was difficult due to the size and the location of the tumor as well as from the adhesions resulting from the previous operation. However, it was completed apparently with success. The patient awoke from anesthesia with no new neurological deficit, and had an initially normal postoperative course, except for a couple of episodes of slowing of respiration, which lasted no more than three hours and appeared to subside on the second postoperative day. However she had a fatal apnea during sleep three days following operation. Sleep-induced 
apnea, possibly related to surgical injury of the medullary respiratory centers, was presumed in this case (Guidetti and Spallone 1980).

The second fatality occurred in a 25 year old man described in detail in a previous paper (Guidetti and Spallone 1980). He had undergone intradural exploration elsewhere with a misdiagnosis of intramedullary tumor. He came to our observation in extremely bad general and neurological condition, but showed remarkable recovery after removal of an anterior neurinoma originating from the $\mathrm{C}_{2}$ root, which had been missed at the previous operation. However be developed wound dehiscence with CSF leak 12 days following operation. Wound revision did not prevent recurrence of the leak, and septic complications eventually supervened. The patient died from meningitis 25 days after surgery.

The third fatality related to surgery occurred in a 51 year old woman with a large anterior craniospinal meningioma. The tumor was approached from the right cerebello-pontine angle. The right vertebral artery, which was deeply embedded in the tumor, was inadvertently injured during piecemeal removal of the lesion. Bleeding from the artery was controlled, and removal of the mass eventually proceeded uneventfully. However the patient awoke with a syndrome of lateromedullary infarction and remained severely disabled. She died in a nursing home a few months later. In the remaining 23 cases the early postoperative course was as a rule free of significant complications. Reoperations were not required except in one patient (case 21), who developed communicating hydrocephalus following uneventful removal of a $\mathrm{C}_{1}$ antero-lateral neurinoma. She recovered completely following ventricular shunting. Of these 23 patients, one requires some form of assistance at home, but he is able to perform most of his daily activities without help. Two patients died from unrelated causes 14 and 28 years after surgery. The remaining 20 patients are presently leading normal lives. A mild weakness, already present preoperatively, was still observed in three of these patients when last seen. Neurological examination was grossly normal in the remaining patients. Follow-up in these cases ranges from 2 to 34 years. Equally good long-term results have been recently reported in a large number of patients from the Mayo Clinic (Meyer et al. 1984). These authors reported a better surgical mortality (5\%) than ours, but a further $5 \%$ deaths from recurrence, while we had no cases of incomplete tumor removal and know of no recurrences.

\section{References}

1. Abrahamson I, Grossman M (1923) Tumors of the upper cervical cord. J Nerv Ment Dis 57: 342-363

2. Aring CD (1974) Lesions about the junction of medulla and spinal cord. JAMA 229: 1879 
3. Arseni C, Ionesco S (1960) Contribution a l'étude des tumeurs située au niveau $\mathrm{du}$ foramen magnum occipitale. Psychiatr Neurol Neurochir 63: 170-183

4. Arseni C, Maretsis M (1974) Tumors of the lower spinal cord associated with increased intracranial pressure and papilledema. J Neurosurg 27: 105

5. Bartal AD, Heilbrom YD, Schiffer J (1972) Dumbbell anterolateral spinocranial neurofibroma with a note on thigh muscle atrophy and fasciculation. Neurochirurgia 4: 143-148

6. Beatty RA (1970) Cold dysesthesia: a symptom of extramedullary tumors of the spinal cord. J Neurosurg 33: 75-78

7. Blom S, Ekbom KA (1962) Early clinical signs of meningiomas of the foramen magnum. J Neurosurg 19: 661-664

8. Bogorodinskij DK (1936) Syndrome of craniospinal tumor (in Russian). Tashkent, Govt Publ USSR, pp 104

9. Brain WR, Northfield D, Wilkinson M (1952) The neurological manifestations of cervical spondylosis. Brain 75: 187-225

10. Bucy PC, Gustafson WA (1938) Intradural lipoma of the spinal cord. Zbl Neurochir 3: 341-349

11. Bull J (1974) Missed foramen-magnum tumours. Lancet 1: 91

12. Cohen L (1975) Tumors in the region of the foramen magnum. In: Vinken PJ, Bruyn GW (eds) Handbook of Clinical Neurology, vol 18. North-Holland Publ Co, Amsterdam Oxford, pp 719-729

13. Cohen L, McRae D (1962) Tumors in the region of the foramen magnum. $\mathbf{J}$ Neurosurg 19: 462-469

14. Craig W McK, Brown JR, Osborn JE (1956) Tumor of the foramen magnum. Neurology (Minneap) 6: 73-76

15. Crockard HA (1985) The transoral approach to the base of the brain and upper cervical cord. Annals of the Royal College of Surgeons of England 67: $321-325$

16. Crockard HA, Bradford R (1985) Transoral-transclival removal of a schwannoma anterior to the craniocervical junction. J Neurosurg 62: 293-295

17. Cushing H, Eisenhardt L (1938) Meningiomas: their classification, regional behaviour, life history and surgical end results. Ch C Thomas, Springfield, $785 \mathrm{pp}$

18. Delmas A (1975) Voies et centres nerveux. Masson et Cie, Paris

19. Du Boulay GH, McDonald JS (1964) Elusive tumors in the cervical spinal canal. Br J Radiol 37: 465-468

20. Elsberg CA (1925) Tumors of the spinal cord and the symptoms of irritation and compression of the spinal cord and nerve roots. Pathology, symptomatology, diagnosis and treatment. PB Hoeber, Inc, New York, 421 pp

21. Elsberg CA, Strauss I (1929) Tumors of the spinal cord which project into the posterior cranial fossa. Arch Neurol Psychiatry 21: 261-273

22. Ferraro A, Barrera SE (1934) Effects of experimental lesions of posterior columns fibers in Macacus Rhesus monkeys. Brain 57: 307-332

23. Fry RE, Fry WS (1980) Extracranial carotid injuries. Surgery 88: 581-587

24. Gabrielsen TO, Seeger JF (1973) Vertebral angiography in the diagnosis of intraspinal masses in upper cervical region. Neuroradiology 5: 7-12 
25. Guidetti B (1958) Mielopatie da spondilosi cervicale. Ed Bologna medica, pp 131

26. Guidetti B, Spallone A (1980) Benign extramedullary tumors of the foramen magnum. Surg Neurol 13: 9-17

27. Hirano H, Suzuki H, Sakakibara T, Inoue K, Muramatsu T (1983) Foramen magnum and upper cervical cord tumors - diagnostic problems - . Clin Orth Rel Res 176: 171-177

28. Hirata Y, Matsukado Y, Kaku M (1985) Syringomyelia associated with a foramen magnum meningioma. Surg Neurol 23: 291-294

29. Howe JR, Taren JA (1973) Foramen magnum tumors: Pitfalls in diagnosis. JAMA 225: 1061-1066

30. Koempf D, Botzler D (1980) Foramen magnum tumor. Presenting as chronic hemifacial pain. An unusual case. Klin Neurol Med Hochsch 51/7: 438-441

31. Krayenbühl H (1973) Special clinical features of tumours of the foramen magnum. Schweiz Arch Neurol Neurochir Psychiatr 112: 205-218

32. Krenkel W, Friedmann G (1967) Diagnose und Therapie der kraniospinalen Tumoren. Fortschr Neurol Psychiatr 35: 237-262

33. Lazorthes G (1961) Vascularisation et circulation cérebrales. Masson \& Cie, Paris, pp 1-164

34. Limas C, Tio FO (1972) Meningeal melanocytoma ("melanotic meningioma"). Its melanocytic origin as revealed by electron microscopy. Cancer 30: 12861294

35. Liveson JA, Ransohoff J, Googold J (1973) Electromyographic studies in a case of foramen magnum meningioma. J Neurol Neurosurg Psychiatry 36: 561-564

36. Lové JG, Adson AW (1941) Tumors of the foramen magnum. Trans Am Neurol Assn 67: 78-81

37. MacCarty CS, Lougheed LE, Brown JR (1959) Unusual benign tumor at the foramen magnum: a report of case. J Neurosurg 16: 463-467

38. Malis LI (1958) The myelographic examination of the foramen magnum. Radiology 70: 196-221

39. Marc JA, Schechter MM (1975) Radiological diagnosis of mass lesions within and adjacent to foramen magnum. Radiology 114: 351-365

40. Margolis MT (1976) A simple myelographic maneuver for the detection of mass lesions at the foramen magnum. Radiology 119: 482-485

41. Metzger J, Helias A, Messimy R, Fohanno D, Aubin ML, De Holanda G (1971) L'apport de la myélobulbographie gazeuse au diagnostic des tumeurs du trou occipital. Neurochirurgie 17: 497-514

42. Meyer FB, Ebersold MJ, Reese DF (1984) Benign tumors of the foramen magnum. J Neurosurg 61: 136-142

43. Miller E, Crockard A (1987) Transoral transclival removal of anteriorly placed meningiomas of the foramen magnum. Neurosurg 20: 966-988

44. Misch W (1935) Meningeal lipomas in the foramen magnum. J Neurol Psychopathol 16: 123-129

45. Mullan S, Naunton R, Hekmat-Panah J, Vailati G (1966) The use of an anterior approach to ventrally placed tumors in the foramen magnum and vertebral column. J Neurosurg 24: 536-543 
46. Netter FH (1983) The Ciba collection of medical illustrations: nervous system. Part I: Anatomy and physiology. Brass A (ed), West Caldwell, NJ, pp 236

47. Nittner K (1975) Spinal meningiomas, neurinomas and neurofibromas and hourglass tumors. In: Vinken PJ, Bruyn GW (eds) Handbook of clinical neurology, vol 20. North-Holland Publ Co, Amsterdam Oxford, pp 177-322

48. Pásztor E (1985) Transoral approach for epidural craniocervical pathological processes. In: Symon L et al (eds) Advances and Technical Standards in Neurosurgery, vol 12. Springer, Wien New York, pp 126-170

49. Rubinstein JE (1938) Astereognosis associated with tumors in the region of the foramen magnum. Arch Neurol Psychiatry 39: 1016-1032

50. Salazkin MA (1953) Classification, clinical and diagnostic features of tumors extending through the foramen magnum (in Russian). Vopr Neirochir 6: 22-28

51. Scholten ET, Hekster REM (1977) Visualization of the craniocervical subarachnoid spaces. Neuroradiology 14: 139-141

52. Shīshikina AV, Kuvshinova RL (1961) La clinique des tumeurs craniospinales (in Russian). J Neurop Psich 61: 501-504

53. Smolik EA, Sachs E (1954) Tumors of the foramen magnum of spinal origin. J Neurosurg 11: 161-172

54. Spallone A (1982) Giant, completely thrombosed intracranial aneurysm simulating tumor of the foramen magnum. Surg Neurol 18: 372-376

55. Spallone A, Tanfani G, Vassilouthis J, Dazzi M (1980) Benign extramedullary foramen magnum tumors: diagnosis by Computed Tomography. J Comput Assist Tomogr 4: 225-229

56. Stein BM, Leeds NE, Taveras JM, Pool JL (1963) Meningiomas of the foramen magnum. J Neurosurg 20: 740-751

57. Stevenson GC, Stoney RJ, Perkins RK, Adams JE (1966) A transcervical transclival approach to the ventral surface of the brain stem for removal of a clivus chordoma. J Neurosurg 24: 544-551

58. Symonds CP, Meadows SP (1937) Compression of the spinal cord in the neighbourhood of the foramen magnum. Brain 60: 52-84

59. Taylor AR, Byrnes DP (1974) Foramen magnum and high cervical cord compression. Brain 97: 473

60. Tristan TA, Hodes PJ (1958) Meningiomas of the posterior cranial fossa. Radiology 70: 1-14

61. Vancoillie P, Veiga-Pires JA (1979) Cervical neurofibroma and generalised spinal stenosis in von Recklinghausen disease. Lancet 8: 1246-1247

62. Weinstein EA, Wechsler IS (1940) Dermoid tumor in the foramen magnum with astereognosis and dissociated sensory loss. Arch Neurol Psychiatry 44: $162-170$

63. Yasuoka S, Okazaki H, Daube JR, MacCarty CS (1978) Foramen magnum tumors. J Neurosurg 49: 828-838 